\title{
Health Care in Saskatoon's Inner City: A Comparative Study of Native and Non- Native Utilization Patterns
}

\author{
Native Issues No. 3 \\ by James B. Waldram \& Mellisa M. Layman \\ 1989
}

The Institute of Urban Studies

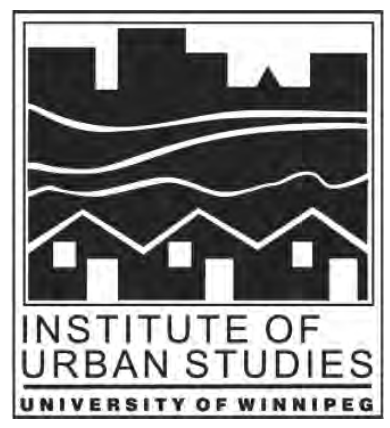



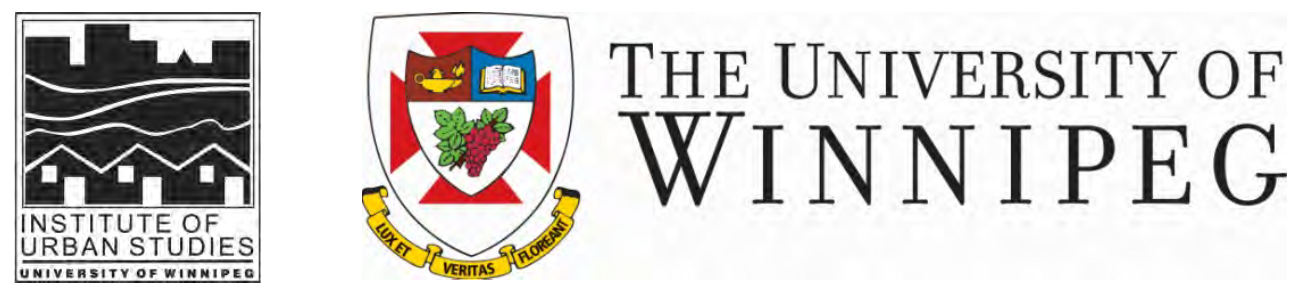

FOR INFORMATION:

The Institute of Urban Studies

The University of Winnipeg

599 Portage Avenue, Winnipeg

phone: 204.982.1140

fax: 204.943.4695

general email: ius@uwinnipeg.ca

Mailing Address:

The Institute of Urban Studies

The University of Winnipeg

515 Portage Avenue

Winnipeg, Manitoba, R3B 2E9

\section{Health Care in Saskatoon's Inner City: A Comparative Study of Native and Non- Native Utilization Patterns \\ Native Issues No. 3 \\ Published 1989 by the Institute of Urban Studies, University of Winnipeg (C) THE INSTITUTE OF URBAN STUDIES}

Note: The cover page and this information page are new replacements, 2015.

The Institute of Urban Studies is an independent research arm of the University of Winnipeg. Since 1969, the IUS has been both an academic and an applied research centre, committed to examining urban development issues in a broad, non-partisan manner. The Institute examines inner city, environmental, Aboriginal and community development issues. In addition to its ongoing involvement in research, IUS brings in visiting scholars, hosts workshops, seminars and conferences, and acts in partnership with other organizations in the community to effect positive change. 
HEALTH CARE IN SASKATOON'S INNER CITY:

A COMPARATIVE STUDY OF NATIVE

AND NON-NATIVE UTILIZATION PATTERNS

Native Issues 3

James B. Waldram

and

Mellisa M. Layman

Institute of Urban Studies

1989 


\section{PUBUCATION DATA}

Waldram, James B. and Mellisa M. Layman

Health Care in Saskatoon's Inner City: A Comparative Study of Native and Non-Native Utilization Patterns

(Native Issues; 3)

ISBN: $0-920213-78-2$

I. University of Winnipeg. Institute of Urban Studies II. Title. III. Series: Native Issues (University of Winnipeg, Institute of Urban Studies); 3.

This publication was funded by the Canada Mortgage and Housing Corporation, but the views expressed are the personal views of the author(s) and the Corporation accepts no responsibility for them.

Published by:

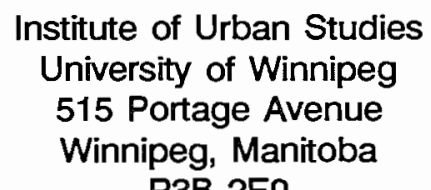

R3B 2E9 
CONTENTS

Contents

iii

Tables

Acknowledgements

$\mathrm{v}$

Section

INTRODUCTION

URBAN NATTVE HEALTH ISSUES

THE SASKATOON STUDY

NATIVE HEALTH CARE IN SASKATOON

METHODOLOGY

DEMOGRAPHIC AND SOCIO-ECONOMIC ANALYSIS

RESULTS OF THE STUDY

HEALTH CARE UTILIZATION PATTERNS

Non-Emergency Treatment $\quad 17$

Family Physician 18

Last Visit to Family Physician 18

Last Physical Examination 19

Perceived Importance of a Family Physician $\quad 20$

Hospital Admissions $\quad 20$

Dental and Visual Health Care $\quad 22$

Emergency Treatment $\quad 23$

Utilization of Hospital Emergency Departments (EDs)

Utilization of Medi-Clinics $\quad 27$

Onset of Symptoms $\quad 28$

RELATED PROBLEMS IN HEALTH CARE UTILIZATION

Clinical Communication Problems $\quad 28$

$\begin{array}{ll}\text { Pharmacy Utilization } & 30\end{array}$

$\begin{array}{ll}\text { Paying for Prescription Drugs } & 30\end{array}$

Paying for Non-Prescription Medicines $\quad 30$

Medicine Literacy

Transportation $\quad 33$

Making Appointments

Babysitting $\quad 33$

UTILIZATION OF THE WESTSIDE CLINIC

Accessing and Utilizing the Westside Clinic $\quad 34$

Appointments and Drop-Ins $\quad 35$

$\begin{array}{ll}\text { The Impact of the Westside Clinic } & 36\end{array}$ 
TRADITIONAL MEDICINE

Indian Healers in the Clinic 42

Previous Contact with Traditional Medicine 43

Beliefs concerning Indian and Western Medicine 45

Traditional Medical Services in Saskatoon 46

SUMMARY AND CONCLUSIONS

REFERENCES 


\section{TABLES}

Page

Comparison of Westside Clinic and Friendship Inn Samples 12

Socio-Economic and Demographic Analysis 13

Residential Data $\quad 15$

Cultural Background of Respondents $\quad 16$

Facility for Non-Emergency Treatment $\quad 17$

Perceived Importance of a Family Physician $\quad 20$

Hospital Admissions in the Last Year $\quad 21$

Admissions to Saskatoon Hospitals $\quad 21$

Last Dental Visit $\quad 22$

Respondents with a Regular Dentist $\quad 22$

Last Eye Examination $\quad 23$

Choices for Emergency Treatment $\quad 24$

Visits to Emergency Departments in the Last Year $\quad 25$

Time of Day for Emergency Department Visits $\quad 26$

$\begin{array}{ll}\text { Problems Understanding Medical Language } & 29\end{array}$

$\begin{array}{ll}\text { Problems Understanding a Physician's Instructions } & 29\end{array}$

Medicine Identification 31

Ability to Indicate Correct Dosage--Natives Only 32

Respondents with Regular or Family Physician $\quad 37$

Last Visit to Family Physician $\quad 37$

Time of Day for ED Visits $\quad 38$

Time of Day for Native ED Visits $\quad 38$

Time of Day for Non-Native ED Visits $\quad 39$

Last Visit to Family Physician $\quad 40$

Last Visit to Family Physician by Native Respondents $\quad 40$

Last Visit to Family Physician by Non-Native Respondents 40

Visits to Hospital Emergency Departments in Last Year 41

Problems Understanding Physician's Instructions (Native Respondents Only) 41 


\section{ACKNOWLEDGEMENTS}

Funding for this study was provided by the University of Saskatchewan under the President's SSHRCC research program and through the College of Arts and Science. The staff at the Westside Clinic and the Friendship Inn were totally supportive of the research and made every effort to ensure its success, for which we are grateful. We would especially like to thank Dr. Stephen Helliar, Dr. Philip Loftus, Sheila Braidek and Marg Cloak at the Westside Clinic, and Lee Smith, formerly the Director of the Friendship Inn. Thanks are also due to Judith Martin of the Saskatoon Community Clinic for permission to undertake this study. Research assistance was provided by Grace Leier, for which we are grateful. However, we alone bear responsibility for any errors found in the report, and the views expressed herein are not necessarily those of the Westside Clinic, the Saskatoon Community Clinic, the Friendship Inn, the University of Saskatchewan, or any of the personnel of these institutions. 


\title{
HEALTH CARE IN SASKATOON'S INNER CITY: A COMPARATIVE STUDY OF NATIVE AND NON-NATIVE UTILIZATION PATTERNS
}

\author{
James B. Waldram and Mellisa M. Layman \\ Department of Native Studies \\ University of Saskatchewan \\ Saskatoon, SK S7N OWO
}

\section{INTRODUCTION}

This report presents an overview of the findings of the "Westside Clinic-Friendship Inn" exploratory study into the health care utilization patterns of urban Native and non-Native people in the west core area of Saskatoon. The focus of the research was upon Native utilization patterns and a general hypothesis was formulated, guided by the existing literature, that suggested that Natives tend to "underutilize" or "inappropriately" utilize urban health care facilities and services in relation to non-Natives. Pragmatic in design, the intent of the research was to investigate this hypothesis as well as to provide a data base and recommendations that would contribute to an improvement in health care delivery in the west core area of downtown Saskatoon.

\section{URBAN NATIVE HEALTH ISSUES}

The Constitution Act of 1982 recognizes the existence of three groups of aboriginal people in Canada: Indians, Inuit and Métis (the situation of the non-status Indians has not yet been defined). Most of these aboriginal or Native people, some $70 \%$ (DIAND, 1980, p. 12), are still found in rural and remote areas, and in the case of the Indians, on federally recognized reserves. But many Native people also live in cities (approximately $30 \%$ of the status Indians, for instance) and urban migration combined with natural population growth has given Native people a strong visible presence in many urban areas, especially those in Western Canada. The movement to the cities has usually been undertaken to improve educational and employment opportunities, although the sad fact remains that many urban Native people do not fulfil their aspirations and remain relatively impoverished (Clatworthy and Hull, 1983). The formation of Native ghettos or Native concentrations in various parts of these cities, including but not limited to the inner city, has sometimes resulted.

The health status of and delivery of health care services to urban Native people is a poorly researched area, and little attention has ever been paid to the extent to which they are adequately served (Shah and Farkas, 1985). A number of studies of urban adaptation by Natives have been undertaken since the 1970s, but only a few have examined Native health care to any extent. After describing the relatively poor state of Indian health in British Columbia in relation to non-Natives, Stanbury (1975) presented data on health care utilization both on a province-wide basis and for the city 
of Vancouver. He noted, for instance, that status Indians "consumed twice as many patient days of hospital care, per capita" in comparison with non-Natives (1975, p. 141). In his examination of "off-reserve" data, Stanbury determined that Indian women tended to visit doctors almost twice as many times a year as men (6.14 to 3.34 visits), and that "the average number of visits to doctors increased with age and decreased with the level of education" (1975, p. 149). Thirty-eight percent of Stanbury's sample indicated that they had located a physician through a clinic or hospital, while $25 \%$ located one through a friend or relative. In Vancouver itself, friends and relatives were more important for contacts with physicians than clinics or hospitals.

In his concluding remarks, Stanbury noted that the "health gap" between Natives and non-Natives was slowly closing, but cautioned that "much of the 'health problem' is a poverty problem" and therefore the gap was likely to remain until such time as the socio-economic position of Natives improved (1975, pp. 153-154). Stanbury's explanation represents one of the few attempts to link poverty with health and health care utilization for Native people.

Don McCaskill, in his 1979 thesis on Native people in Winnipeg, Toronto, Edmonton and Vancouver, noted that most Native people accessed some form of urban health care in the city, although there were extensive variations in the services utilized (1979). For instance, in Winnipeg, approximately half of McCaskill's sample reported receiving medical care from public outpatient clinics, and only $18 \%$ from private physicians (1979, p. 43). A similar picture emerged from his Toronto data, in which he discovered that $41 \%$ of the respondents received their medical care as out-patients or from public clinics, and only one-quarter of the sample reported having regular physicians outside the clinic setting. McCaskill's data on Native health care utilization patterns in Edmonton and Vancouver also emphasized the significance of clinics and other "drop-in" style sources of health care. Some $34 \%$ of the sample in Toronto indicated having their own dentist, although $39 \%$ indicated having never received dental care in the city.

More recently, there have been a number of studies of urban Native people which have, in a cursory manner, added a little to our knowledge of their health and health care utilization patterns. The most comprehensive of these was undertaken by Mears et al. in the "skid row" area of Vancouver (1981). The authors of this study conducted 94 interviews, and covered a wide range of topics, from self-perceptions of health to utilization of various health facilities and services. Overall, $89 \%$ of their respondents reported having seen a physician in the previous year, with the most common reason for the visit being a "check-up." Only $7 \%$ were unhappy with the care they had received. Some $54 \%$ of the respondents reported having seen a dentist in the previous two years; no data were provided on optometric services. 
Mears et al. also reported the relatively high utilization of the "Downtown Health Clinic:" $66 \%$ of the respondents reported having used it in the previous two years. The authors concluded that The clinic is used for many of the same reasons as the doctor, which supports the idea that many of the patients are using the clinic physicians as their regular doctor" (1981, p. 72). The local hospital emergency department was another important source of health care, with almost $27 \%$ of the respondents having utilized it (over how long a period of time is unclear from the report) for various injuries and poisonings which, the authors point out, are the products of skid row life. The utilization of the traditional Indian medical system was not extensive. Overall, only $10 \%$ reported ever having consulted with a traditional healer; leading the authors to conclude "that not many people in the city are using their traditional medical culture" (Mears et al., 1981, p. 74).

An interesting aspect of the study by Mears et al. was that they also interviewed various medical practitioners and employees of social service agencies regarding their views of Indian health and health care. As they note, $41 \%$ of these professionals stated their belief that socio-economic conditions and lack of education were responsible for the health conditions of Vancouver skid row Indians. Further, 92.5\% stated that "fear/lack of trust/shyness/embarrassment" were the main reasons why Natives are hesitant about seeking medical care $(1981$, p. 85). The authors conclude that, "The view of Indians by the professionals shows a high degree of dissatisfaction with Indians as patients," in part because of their "irregularity in keeping appointments," but also due to the fact that one-quarter of the professionals expressed problems communicating with their Indian patients.

Overall, Mears et al. argue that Indians may be well served by health facilities on the reserves, but once they come to the city, they enter a complex world of jurisdictions, anomalous statuses and contradictions. They do not know where to get the services they require, and many of the people who provide certain services cannot guide them to others (1981, p. 45).

The authors assert that this problem of access is ultimately "closely bound up with the existing patterns of government services and the generally depressed conditions of the lower portion of Canada's Indian community" (1981, p. 3). Hence, their report is somewhat confusing in that, while they fully accept Stanbury's (1975) poverty explanation, they nonetheless imply that Indian urban dwellers lack knowledge of the health care system and cannot seem to figure it out.

Three other recent studies, one involving a number of urban centres in Ontario, the other two in Calgary and Edmonton, have added only minimally to our knowledge in the area of Native health care utilization. In each case, utilization was measured only by a handful of questions as part of larger Native "needs assessment" studies. 
The Ontario study, a task force investigation of "Native People in Urban Settings" involving "approximately 3000" respondents, provided little quantitative data on health, but argued that in general Native people made frequent use of urban health care services, and demonstrated a high degree of satisfaction with them (Maidman, 1981). Those individuals "least likely" to have a family physician were males, recent migrants to the city, transients, and Treaty Indians. There were also some problems identified in understanding the variety of medical insurance schemes available in Ontario.

In Calgary, interviews with 402 Native residents indicated that, although $31 \%$ of the males regularly sought health care from a hospital emergency department, only $7.0 \%$ of the females did likewise. In contrast, $80 \%$ of the females reported seeking regular health care from a "family doctor," in comparison with $48 \%$ of the males. More males (18\%) than females (5\%) reported not having a regular or family physician; those in lower monthly income brackets were less likely to have a regular physician. Individuals under age $\mathbf{4 0}$ were more likely to go to a hospital emergency department, while those over age 40 were more likely to seek out a physician. The Calgary data also revealed that more Native women $(42 \%)$ than men $(28 \%)$ had sought health care within the previous month. While no data were provided on the utilization of traditional medicine, the report noted that "Only a small percentage of individuals in any age category had obtained health care from a Native doctor" (1984, p. 35). Overall, $77 \%$ of the respondents indicated that they did not have any difficulty in seeing a doctor or obtaining health care.

In the Edmonton study (Alberta, 1985), 384 Native residents were interviewed, of which 62\% stated that they obtained health care from their "family doctor." A further $12 \%$ stated that they obtained health care from a hospital emergency department, and $10 \%$ from a health clinic. Ninety-one percent of the respondents reported that they did not experience problems obtaining health care when needed.

The Saskatchewan Senior Citizens' Provincial Council (SSCPC, 1988) published the findings of their needs assessment study of "off-reserve" Native elderly in 1988. Methodologically, it is not possible to determine which of their respondents were living in urban centres, and which were in smaller communities or rural areas. Nonetheless, the study does provide some insights, and it demonstrates that Native elderly were making extensive use of the health care system. For instance, $41.5 \%$ of the Native elderly in the Southern regions of the province reported eight or more visits to a physician in the previous year, which is twice as high as reported for Canadian seniors as a whole. In the North, only $24.1 \%$ of the respondents reported eight or more medical visits. Given that the medical problems of both Northern and Southern Native elderly were essentially the same, the report's authors are led to conclude that, "the frequency of medical visits of the elderly in the north relate more to the question of access than to the question of need" $(1988$, p. 108). 
This study also made reference to the likelihood that "many of the physician contacts reported by the Indian and Métis elderly take place in a hospital or an emergency room setting" (SSCPC, 1988, p. 109), but they were unable to present conclusive data for emergency department utilization. They did note, however, that having a telephone was a very important means by which senior citizens make appointments with physicians, and that $33 \%$ of the seniors in the South, and $53 \%$ in the North, were without telephones. Further, they also noted that "frequent changes of residence by Native seniors might complicate ties with a neighbourhood or community-based physician or clinic" (1988, p. 110).

Two recent papers by Shah and Farkas (1985) and Farkas and Shah (1986) have summarized the health care problems of urban Native people from the existing literature. These authors note that "information about their health status suggests that they have many unmet needs, but this information is fragmented, lacks quantifiable data and is seldom readily available or cited in a manner that can be retrieved from usual literature sources" (1986, p. 274). They argue that this literature suggests that "Indians who migrate to cities continue to have many of the health problems seen on reserves, but these are augmented by the stress of adaptation to urban living, unfamiliarity with urban health care systems, which often differ dramatically from the community-based health care systems on reserves, and Native-non-Native communication problems" (1985, p. 859).

Shah and Farkas (1985) also describe the "barriers" to health care utilization that Native people experience. These include: Native "social patterns," such as the sharing of money and different concepts of time; communication problems between Native patients and non-Native health practitioners, some of which are simply linguistic, while others are cultural (e.g., different patterns in asking and responding to questions); lack of familiarity with urban health care services; lack of culturally sensitive health care; and lack of medical records on Native patients (especially for those who have recently migrated to the city). While acknowledging the widespread poverty of urban Natives, these authors do not view poverty per se to be at the root of utilization problems.

The data that do exist on Native health care tend to point in contradictory directions. For instance, while Shah and Farkas (1985) imply that there are significant utilization problems, and some studies such as the Vancouver report by Mears et al. (1981) describe a Native population with apparent problems in this area, other studies suggest that utilizing urban health care facilities is not particularly difficult for Native residents. However, the nature of the data prevents us from truly comparing the situations in each city. For instance, we do not know if the socio-economic situation of Native respondents is uniform in the Ontario, Winnipeg, Toronto, Edmonton or Calgary studies. If a significant number of these respondents are not "skid row" residents, as in the Vancouver study of Mears et al. (1981), then of course it is not possible to compare them. In this case, a "poverty" explanation might 
seem most appropriate: in Vancouver, the Native respondents utilized the health care system in a particular manner because they were poor, and not because they were Native. Shah and Farkas (1985) fail to reconcile these different observations, or to point out the varied experiences of different Native people in different cities (and areas of cities) in different parts of Canada. Logically, there is no one single adaptation to cities by Native people: some do quite well, others less so, and still others find themselves gripped by chronic unemployment and ill-health.

A number of broad research questions emerge from the examination of the literature. These include:

1. What is the relative importance of poverty, culture and language in understanding the adaptation of Native people to the urban health care system?

2. What is the relative importance of other socio-economic factors in understanding health care utilization, such as sex, age and employment status?

3. Which kinds of facilities and services--private physicians, clinics, hospitals, etc.--are used by Natives for primary health care, and why?

4. To what extent are traditional Indian medical systems still relevant for urban Native people?

The current research was guided by these questions.

Clearly, the city presents a variety of health care options which may be unfamiliar and even intimidating to the new migrant. The health care system that characterizes Indian reserves and rural or remote Native communities usually involves only a single agency, delivering or arranging the delivery of all primary health care services. The existence of racism among medical personnel may detract from the utilization of urban health services by the long-term resident. Whatever the reason, it has been argued that urban Native people tend to avoid contact with the Western medical system, often consulting the physician only after an illness has failed to resolve itself. Further, it has been argued that urban Native people are significantly less likely to have established a relationship with a particular physician, and are more likely to utilize emergency services at local hospitals for non-emergency medical treatment. It is often assumed that Native people both underutilize and misuse the urban health care system. Presumably the result is a less than optimum level of health. Problematic is the simple fact that existing data, while imperfect in many ways, argue against overgeneralizations in Native health care utilization: in some cases problems seem to exist, in other cases they do not. Further, while many studies frequently refer to "inappropriate" utilization patterns of Native people, or in some cases "underutilization," "overutilization," or simply "misuse" of urban services, nowhere is there an attempt to define these terms or to provide a standard against which to compare Native patterns. More 
importantly, in none of the studies discussed so far are Native utilization patterns compared with those of non-Natives. This is a crucial omission, since without such a comparison we cannot really begin to understand if Native utilization patterns are a product of cultural differences, a product of a century-long process of colonialism, a product of racism within the medical system, or a product of their poverty. The Westside Clinic--Friendship Inn health care study in Saskatoon was designed in part to begin to address these questions.

\section{THE SASKATOON STUDY}

\section{NATIVE HEALTH CARE IN SASKATOON}

Saskatoon is a small Canadian prairie city of some 170,000 people, located in central Saskatchewan. Native people number approximately 140,000 in the whole province (between $10 \%$ and $15 \%$ of the total provincial population), and the number in Saskatoon itself may range from 11,000 to 20,000 (or between $7 \%$ and $11 \%$ of the total city population) (Clatworthy and Hull, 1983; Star-Phoenix, 7 Oct. 1986). Although the Native population is not located in any single area of the city, it has been estimated that it constitutes at least $20 \%$ of the residential population in the west downtown core area (Clatworthy and Hull, 1983, p. 17).

A great deal has been written on the socio-economic circumstances of Native people in Saskatoon, and there is no need for a comprehensive discussion of the literature in this context. The study by Clatworthy and Hull (1983) is by far the most comprehensive, and their data clearly demonstrate the extent to which Saskatoon's Native population consistently registers poorly on virtually all socio-economic indicators. Chronic unemployment and underemployment are facts of life for many Saskatoon Natives, compounded by relatively lower educational levels and larger family sizes. While there are also many non-Natives in the city who are unemployed, and indeed they were also targeted in the Westside Clinic and Friendship Inn study, the Clatworthy and Hull data combined with our own clearly indicate that Native residents are the poorest of the poor.

Relative to the rest of the city, the west downtown core area is characterized by its poverty, and the symptoms are everywhere evident: a relatively high rate of crime for alcohol-related offenses; a relatively high proportion of residential renters to owners; the existence of commercial operations catering to a population of low socio-economic standing, such as hotel beverage rooms, pawn shops and discount stores; and the existence of a variety of social service agencies, such as the Salvation Army and the Friendship Inn. The relative poverty of the west core area is noticeable in contrast to the affluence of the east core area. Not surprisingly, the area is not well-serviced by primary health care facilities. There are only a few private physicians' offices, one clinic, and a hospital. 
According to one analyst, "[Saskatchewan] Indian people who live in urban areas are not faced with a severe problem of access to institutionally based health care" (Anderson, 1984, p. 288). However, simply being surrounded by health care facilities represents an insufficient measure of accessibility. Indeed, it has been recognized by others for many years that a problem might exist in the Native utilization of health services in this area. The Saskatoon Indian and Métis Friendship Centre has defined the problem as follows:

Economic, social and cultural problems pose barriers to good health practices and adequate medical care. Indians coming to Saskatoon from rural reserves face serious adjustment problems. It is difficult for them to use public transportation, keep scheduled appointments or follow directions in rapidly spoken English. Urban Native people do not normally develop a family physician contact, and when sickness strikes, tend to show up at the hospital Emergency Department. Care providers are usually unaware and uninformed about cultural differences and special Indian needs. Consequently, many services provided to Saskatoon Indians are not acceptable to them and therefore are not well utilized (SIMFC, 1982, p. 4).

These views are echoed by the Saskatoon Community Health Unit, whose "Healthy MotherHealthy Baby" program has operated for many years. In 1979, a review of city prenatal services indicated that the needs of pregnant Natives and other low income women were not being met by existing prenatal services (Saskatoon, n.d.). According to the Health Unit, "services were not considered acceptable to Native women and the groups and agencies representing these women were not comfortable in making referrals." Through the employment of Native counsellors, the "Healthy Mother--Healthy Baby" program made "culturally appropriate" prenatal care available to urban Native women, with considerable success.

Outside of the "Healthy Mother--Healthy Baby" program, in the early 1980s there were few other special health programs for urban Native people. Beginning in 1981, in an effort to remedy this situation, the Friendship Centre, in conjunction with private physicians, hospitals and Native political organizations, developed a proposal for the implementation of a "Native health liaison project." The purpose of the project would have been to employ Native health workers in hospitals and in the community to provide certain aspects of health delivery to Native people. Program delivery would have emphasized preventive medicine and utilization of available health care services, and consultation where possible in the appropriate Indian language. In so doing, it was hoped that Native people would have "more opportunity to preserve their own dignity, to have health and illness interpreted in a method that is compatible with Indian culture and modern medicine, and provide a strong foundation for the continuation of Native lifestyles, whether in rural or in urban areas" (SIMFC, 1982, p. 5). However, despite repeated submissions of the proposal to both federal and provincial health agencies, no funding 
has been forthcoming, and the proposal has yet to be implemented. After ten years of annual proposal submissions, in the spring of 1989 the Westside Clinic itself finally received provincial funding to hire a Native community health worker.

Saskatoon has three hospitals, including a university teaching hospital (University Hospital) and two community hospitals (City and St. Paul's Hospitals), and a full range of general practitioner and specialist services. In the west core area of the city, however, there are relatively few medical services. There are but a handful of general practitioners, and the Westside Clinic and St. Paul's Hospital are the two most significant facilities in the area.

The Westside Clinic was established in 1975 to provide primary health care to the underserviced Native and non-Native people of the west core area. It is, in effect, a satellite of the larger Saskatoon Community Clinic established in the east core area in 1962 . It is staffed by two physicians (sharing a two-thirds time position) seconded to the Clinic from the main facility, who usually work solo on different days of the week, plus a clinic aide, a community nurse, a counsellor, and a receptionist. Westside Clinic staff estimate that about $80 \%$ of their patient base consists of Native people, and that the vast majority of all their patients are poor, including a number of homeless persons. As one of the few medical facilities in the west core area, the Westside Clinic has been very concerned with the problems associated with delivering Western-based health care to Native people. They have attempted to make the Clinic as non-threatening as possible, by avoiding the overt use of medical symbols (such as the white coats), providing coffee and a "living room" atmosphere in the waiting room, and even displaying patients' handicrafts in a showcase for sale purposes.

The Friendship Inn is a social service agency located adjacent to the Westside Clinic. The Inn provides both meals and recreational activities to indigent urban residents, both Native and non-Native.

\section{METHODOLOGY}

The research was initiated by the authors in 1987 after a preliminary investigation of urban Native health issues in Saskatoon. The study utilized an interview schedule with 123 closed and/or open ended questions, plus three supplementary interview schedules designed to produce data of direct relevance to the broad research questions raised earlier. Individuals over the age of 16 were targeted. Pre-testing of the instrument took place in September of 1987 at the main Community Clinic, so as to avoid overlap with the residents of the west downtown area. Once revised, the instrument was then administered at both the Westside Clinic and the Friendship Inn. A total of 226 interviews were undertaken between November 1987 and April 1988; interviewing was done intermittently throughout this period, during which there were no changes in the availability of health care services or facilities. 
Overall, 125 (55.3\%) interviews from the Westside Clinic and 101 (44.7\%) from the Friendship Inn were obtained, representing 142 Natives (62.8\%) and 84 non-Natives (37.2\%).

All interviews were conducted in English, and the questions were kept fairly short and simple. As the population in general proved to be quite proficient in English there were few linguistic problems. In only a few cases were language problems in evidence, and these interviews were not used.

Given the nature of the urban population in this area, and the fact that no comprehensive sampling frame existed, a random sample was impossible to achieve. At the Westside Clinic, patients and their companions were approached by the clinic aide and requested to participate in the study. At the Friendship Inn, a sign announcing the study was posted, and individuals interested in participating were directed to the interviewer. Enthusiasm was so great that there were frequently lineups for interviews. Each respondent was given an honorarium of five dollars for participating. There were only a handful of refusals. Nonetheless, we must be cautious not to generalize these findings to the larger urban Native and non-Native communities. This exploratory research was designed to cover a wide array of topics since virtually no research had ever been done on health care in this area. As such, the results will prove useful both for clinical practice and for program and policy development, and will provide a base for future research activity.

The availability sample was clearly biased toward presenting a picture of fairly extensive utilization of health care services. As the research was partly undertaken in a medical clinic, it is quite likely that many respondents were indeed those with a greater commitment to health maintenance. Respondents at the Friendship Inn demonstrated less commitment, yet as a social service agency the Friendship Inn's clientele still demonstrates some desire to seek assistance and relief from the poverty which characterizes this population. The research also concentrated on individuals utilizing these two institutions in the west core area of the city. While most respondents lived in the hinterland around the Clinic and the Friendship Inn, some were from the suburbs. We were concerned primarily with those residents who were relatively impoverished, and hence the results do not necessarily reflect the health care utilization patterns of Natives and non-Natives who are more affluent and/or who live in other areas of the city. Very few homeless respondents were interviewed (of which it is believed there are many, especially in the summer).

When the decision was made to interview at both the Westside Clinic and the Friendship Inn, we assumed that the client base of the two institutions would vary little on important socio-economic variables. Since they are located adjacent to each other, and generally are known to serve disadvantaged urban dwellers, it was assumed that the two research sites would service overlapping 
constituencies. Care was taken to ensure that individuals were not interviewed more than once in either location.

The Westside (WS) and Friendship Inn (FI) samples were virtually identical in terms of employment status, reported annual income, and dependence on social assistance. There was likewise no statistical difference in education between the two samples. However, the FI sample tended to be older than the WS sample. A higher proportion of single and male individuals was reported at the $\mathrm{Fl}$, while WS individuals were more likely to have dependent children. Finally, a higher proportion of non-Natives was interviewed at the Fl. Table 1 presents the relevant data comparing the two samples. Personnel from both institutions have indicated that our samples reflect fairly accurately their view of the clientele. Overall, it is apparent that the two samples complement each other. The WS sample emphasizes a component of the population that includes a large proportion of families and especially single parent families who, we might surmise, would have contact with the health care system in response to the health needs of their children. At the FI we have a sample that concentrates on single males without dependent children whose health care needs and utilization of the health care system might be significantly different. Of course, in each sample we nevertheless have individuals who vary along a variety of criteria. In general, statistical analysis revealed few significant differences between the Westside and Friendship Inn samples in the areas of health care utilization; discernible differences, such as those based on age, sex, marital status, and so on tended to transcend the boundaries of each sample and to be significant for all respondents regardless of where they were interviewed.

Throughout the report, observations will be made with respect to the question of statistical significance. In inferential statistics, a statistically significant observation is one in which the likelihood that the data appear as they do primarily by chance is known, and that likelihood is deemed acceptable. In this research, the 0.05 level, or a $5 \%$ or less chance, was utilized as a guideline to demarcate "statistical significance;" the relevant statistics will be presented where "statistical significance" is achieved or, in a few cases, nearly so, but generally not in cases where no such significance exists. The concept of statistical significance is of particular importance when we wish to generalize from a sample of a population to the population as a whole. Since this research effort was undertaken without the utilization of truly random sampling procedures, generalization to the larger population must be done with great care; descriptive statistics, describing only the sample itself, are entirely appropriate in this case. However, the use of tests of statistical significance for the types of analyses presented 


\section{Table 1}

\section{Comparison of Westside Clinic and Friendship Inn Samples}

(Statistics shown for significant variables only)

Age

WS mean $=32.0$

$T=-2.76$

of $=224$

$\mathrm{FI}$ mean $=36.5$

prob $=0.001$

Education

WS mean $=8.96$ years

$\mathrm{FI}$ mean $=9.38$ years

Income

WS mean $=\$ 7777.74$

$\mathrm{FI}$ mean $=\$ 7135.29$

Employment Status

WS $88.8 \%$ unemployed

FI $86.1 \%$ unemployed

Social Assistance

WS $69.6 \%$ receiving

Fl $69.3 \%$ receiving

Sex

WS $\quad 35.2 \%$ male

$64.8 \%$ female

chi square $=\mathbf{5 5 . 0 1}$

FI $\quad 85.2 \%$ male

$14.8 \%$ female

df $=1$

$\operatorname{sig}=0.000$

Marital Status

WS $\quad 40.8 \%$ single

$37.6 \%$ married

$21.6 \%$ widowed/separated/divorced

chi sq $=11.39$

F1 $\quad 44.5 \%$ single

$18.8 \%$ married

df $=2$

$\operatorname{sig}=0.003$

$36.6 \% \mathrm{widowed} / \mathrm{separated} /$ divorced

Dependent Children

WS $57.6 \%$ have dependent children

chi sq $=31.52$

df $=1$

FI 19.8\% have dependent children

sig $=0.000$ 
here are not to be discounted (cf. Winch and Campbell, 1969). It must also be kept in mind that significance is more difficult to achieve with a small sample, or in the case of this research, sub-samples. Finally, the concept of statistical significance does not infer importance or significance in terms of the research findings.

\section{DEMOGRAPHIC AND SOCIO-ECONOMIC ANALYSIS}

Table 2

Socio-Economic and Demographic Analysis

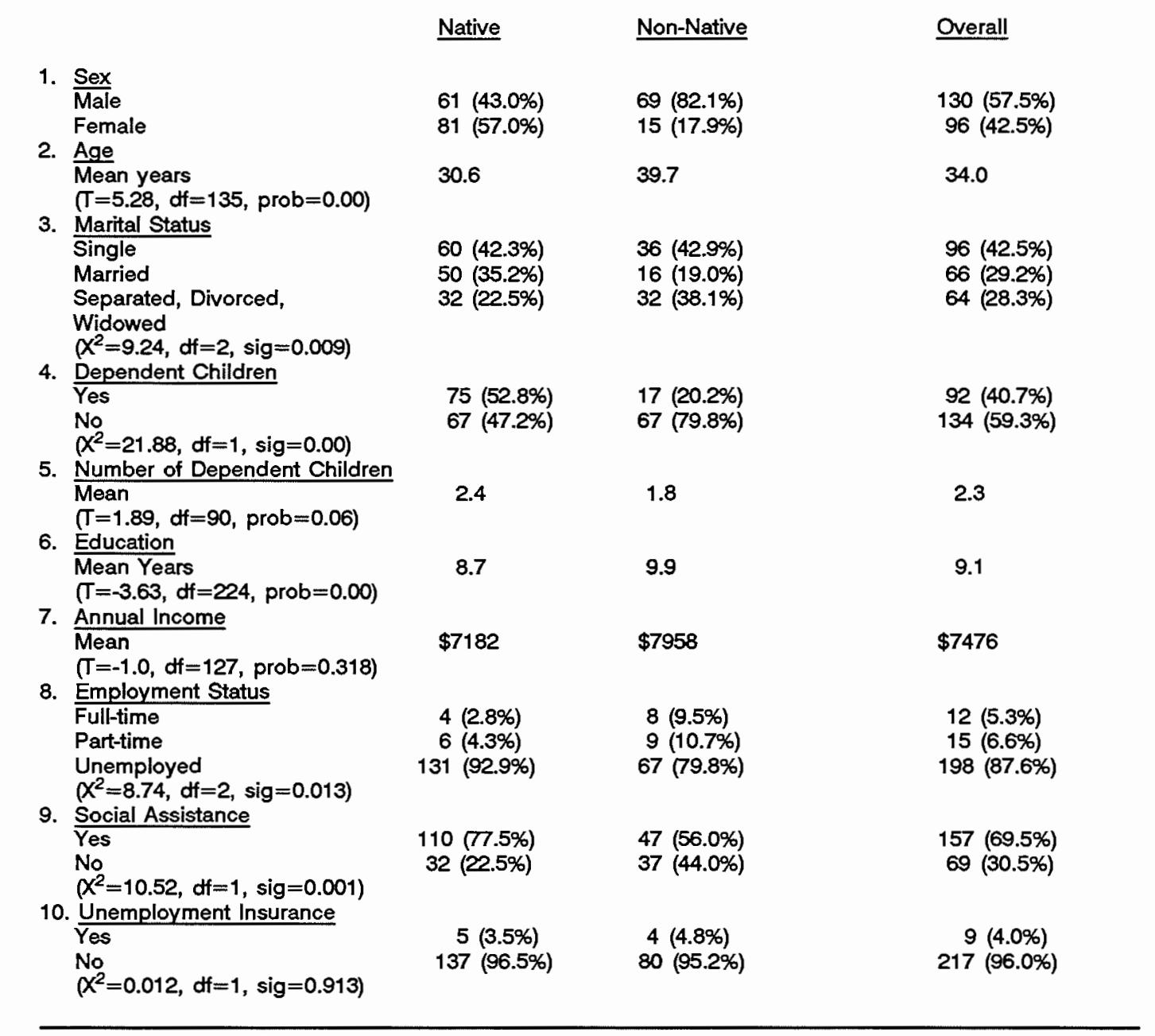

Table 2 presents data on a variety of demographic and socio-economic variables for the Native and non-Native populations. A number of observations are pertinent here. In socio-economic terms, 
the vast majority of the respondents were poor, largely unemployed, and clearly represent the most disadvantaged of all the city residents. There were some differences between Natives and non-Natives in this regard, with the Natives generally demonstrating even lower socio-economic status. Hence, for instance, we can say that while both Natives and non-Natives suffered from widespread unemployment, significantly more Natives $(92.9 \%)$ than non-Natives $(79.8 \%)$ were without jobs at the time of interview. Similarly, while the mean level of formal education was relatively low for the entire sample, the mean Native level of 8.7 years was significantly less than the non-Native mean of 9.9 years.

Demographically, some differences between Natives and non-Natives were observable. Natives in the sample tended to be younger, and there was a higher proportion of females than males in comparison with the non-Native sample. Significantly more Natives than non-Natives reported being married at the time of interview, and hence it is not surprising that significantly more Natives than non-Natives reported having dependent children.

Table 3 presents a variety of residential data for the sample. As we can see, Native respondents reported fewer total number of years resident in the city, and more different places lived within the city in the year previous to interview. The majority of both Natives and non-Natives indicated their current place of residence to be on the west side of the river. Natives reported a higher degree of house rental and living with friends and family, whereas non-Natives reported a higher degree of house ownership and apartment/suite rental. 
Table 3

Residential Data

Native Non-Native $\quad$ Overall

1. Number of places lived in last year

$\frac{1}{2}$
3 or more
(Mann-Whitney $U=4507$, prob $=0.001$ )
$\frac{\text { Mean Number of Places Lived }}{(T=3.59, \text { df }=220, \text { prob }=0.00)}$

Mean

$$
\begin{aligned}
& 58(40.8 \%) \\
& 37(26.1 \%) \\
& 47(33.1 \%)
\end{aligned}
$$

2. Number of Years in City

0 to 1

1 to 5

More than 5

(Mann-Whitney $U=5632$, prob $=0.433$ )

Mean Number of Years in City

$(T=-1.88, d f=224$, prob $=0.061)$

Mean

3. Current Residence Location

West Side

East Side

Not in City

$\left(x^{2}=5.11, d f=2, \operatorname{sig}=0.078\right)$

4. Current Living Arrangements

Rent Apartment or suite

Rent House

Own House

Rent Room

Duplex

Live with Friend or Family

Social Service Agency

No Place

$\left(X^{2}=37.52, \mathrm{df}=7, \mathrm{sig}=0.00\right)$
2.3

$$
\begin{array}{ll}
51 & (60.7 \%) \\
21 & (25.0 \%) \\
12 & (14.3 \%)
\end{array}
$$

1.6

$109(48.2 \%)$

$58(25.6 \%)$

$59(26.1 \%)$

2.1

$25(17.6 \%)$
$41(28.9 \%)$
$76(53.5 \%)$

9.74

$19(22.6 \%)$
$12(14.3 \%)$
$53(63.1 \%)$

$44(19.5 \%)$

(23.5\%)

14.02

129 (57.0\%)

11.3

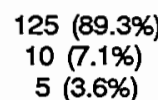

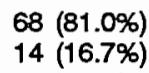

2 (2.4\%)

$193(86.2 \%)$
$24(10.7 \%)$
$7(3.1 \%)$

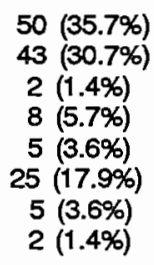
$37(44.6 \%)$
$10(12.0 \%)$
$10(12.0 \%)$
$12(14.5 \%)$
$1(1.2 \%)$
$4(4.8 \%)$
$9(10.8 \%)$
$0(0.0 \%)$

A variety of data were also obtained on ethnic and/or cultural status, and Native status for the Native respondents. Of the total of 226 respondents, some 104 (46\%) stated that they were status Indians; 15 (6.6\%) stated that they were non-status Indians; 23 (10.2\%) stated that they were Métis; and $84(37.2 \%)$ stated that they were non-Native. The most dominant Native cultural groups in the sample were Plains Cree, Saulteaux, Northern Cree and Métis. Non-Native respondents were primarily of Western or Eastern European descent. Table 4 presents these data. 


\begin{tabular}{lrr}
\hline \multicolumn{3}{c}{ Table 4 } \\
\cline { 2 - 2 } Cultural Background of Respondents \\
Cultural Group & $\mathrm{N}$ & $\%$ \\
Northern Cree & 24 & 10.6 \\
Plains Cree & 47 & 20.8 \\
Dene & 3 & 1.3 \\
Dakota & 4 & 1.8 \\
Saulteaux & 35 & 15.5 \\
Métis & 23 & 10.2 \\
Western European & 62 & 27.4 \\
Eastern European & 23 & 10.2 \\
Other & 5 & 2.2 \\
Total & 226 & 100.0 \\
& & \\
\hline
\end{tabular}

English was the first spoken language of $55.3 \%$ of the respondents, followed by Cree $(23.0 \%)$ and Saulteaux (9.7\%). For non-Natives, $86.5 \%$ were Anglophone, and 13.5\% Francophone in terms of their first language. For Natives, $43.6 \%$ stated that English was their first language, followed by Cree (37.1\%) and Saulteaux (15.7\%).

Of the Native respondents (status, non-status and Métis), $44.4 \%$ continue to speak Cree, while $18.3 \%$ continue to speak Saulteaux. Approximately $30.3 \%$ of the Native respondents currently do not speak an Indian language.

\section{RESULTS OF THE STUDY}

\section{HEALTH CARE UTILZATION PATTERNS}

A variety of questions in the interview schedule were designed to elicit data on the patterns of health care utilization of respondents. The focus was upon the kinds of services utilized, and not on the specific circumstances or illnesses and other factors that contributed to the decision making process involved in seeking health care. Through the analysis provided here, we are able to determine the extent to which services are accessed, and hence evaluate the relative utilization by Natives and nonNatives. 


\section{Non-Emergency Treatment}

Only $11.5 \%$ of the respondents reported having difficulty finding a physician or nurse when they wanted one. More Natives (14.1\%) than non-Natives (7.1\%) reported such problems. Most respondents $(52.7 \%)$ stated that for medical problems that were not of an emergency nature, they would go to the WS Clinic. Others stated that they would go to a private physician's office (21.2\%), a medi-clinic (8.6\%) or St. Paul's Hospital (7.2\%), among other options. There exists a significant difference between the sexes, with $76.8 \%$ of the females stating that they would go to the WS, compared with $34.6 \%$ of the males (chi $\mathrm{sq}=39.33, \mathrm{df}=4$, $\mathrm{sig}=0.00)$. In contrast, many more males $(29.9 \%)$ than females $(9.5 \%)$ would go to a private physician; likewise, more males $(11.0 \%)$ than females $(5.3 \%)$ would go to a medi-clinic. Males are also more likely to use St. Paul's Hospital $(9.4 \%$, as compared with $4.2 \%$ for females.)

There is a strong relationship between marital status and utilization of non-emergency services by males. For single males, $11.5 \%$ indicated that they would seek treatment at St. Paul's Hospital, as compared with $3.2 \%$ for married males; $28.1 \%$ of single males indicated they would use WS, compared with $54.8 \%$ of married males. A high percentage of females, either single (80.3\%) or married $(70.6 \%)$ indicated they would use WS. The treatment choices of single people on the basis of sex were statistically significant (chi $s q=41.6, d f=4, s i g=0.000$ ); such was not the case for married people.

Native respondents were more likely to use WS than non-Natives $(67.1 \%$ to $28.0 \%)$ for non-emergency treatment, and utilization of St. Paul's Hospital was about the same for both Natives and non-Natives (around 7.2\%). However, non-Natives were more likely to use a private physician (30.5\% compared with $15.7 \%$ for Natives) or a medi-clinic (14.6\% for non-Natives and $5.0 \%$ for Natives). These results are summarized in Table 5. Logically, those interviewed at WS demonstrated a strong tendency to return there for non-emergency treatment, while those interviewed at FI demonstrated a greater commitment to other facilities, especially private physicians.

\begin{tabular}{|c|c|c|c|c|c|}
\hline \multicolumn{6}{|c|}{$\begin{array}{c}\text { Table } 5 \\
\text { Facility for Non-Emergency Treatment }\end{array}$} \\
\hline & Westside & St. Paul's Hosp. & Medj-Clinic & Private & Other \\
\hline \multicolumn{6}{|l|}{ Status } \\
\hline Native & $\begin{array}{c}94 \\
(67.1 \%)\end{array}$ & $\begin{array}{c}10 \\
(7.1 \%)\end{array}$ & $\begin{array}{c}7 \\
(5.0 \%)\end{array}$ & $\begin{array}{c}22 \\
(15.7 \%)\end{array}$ & $\begin{array}{c}7 \\
(5.0 \%)\end{array}$ \\
\hline Non-Native & $\begin{array}{l}23 \\
(28.0 \%)\end{array}$ & $\begin{array}{c}6 \\
(7.3 \%)\end{array}$ & $\begin{array}{c}12 \\
(14.6 \%)\end{array}$ & 25 & $\begin{array}{c}16 \\
(19.5 \%)\end{array}$ \\
\hline chi sq $=36$ & $g=0.00$ & & & & \\
\hline
\end{tabular}




\section{Family Physician}

Most respondents $(77 \%)$ indicated that they had a family physician, and virtually all were able to name him or her. A higher percentage of females $(84.2 \%)$ than males $(73.4 \%)$ stated that they had family physicians. There was some difference between those with children who had family physicians $(85.7 \%)$ and those without $(72.7 \%$ ) (chi $s q=4.57, d f=1, \mathrm{sig}=0.033$ ). While more single females $(86.7 \%)$ than males $(72.2 \%$ ) had family physicians, (chi $s q=3.7, d f=1$, sig=0.055), there was little difference between married males and females.

There was little difference between Natives and non-Natives in having a family physician: $79.4 \%$ of the Natives, and $75.6 \%$ of the non-Natives reported having one. Similarly, virtually all could provide the name of their physician. While the age of the respondent was not an important factor for the overall sample for the non-Natives, age did prove to be significant for the Natives, with those reporting a family physician registering a higher mean age (31.3 years) than those without one (27.7) $(t=2.57, \mathrm{df}=96.6$, prob=0.012).

The number of years in total that the respondent had lived in the city is clearly an important factor. For those in the city for one year or less, $52.3 \%$ were without a family physician. This compares with $22.6 \%$ for those in the city between one and five years, and $11.1 \%$ for those in the city more than five years (Mann-Whitney $U=2391$, prob $=0.000$ ).

There was little difference in the proportion of respondents having a family physician between the WS and FI samples. Not surprisingly, the majority of those interviewed at the WS (68.4\%) who had a family physician stated that this individual was indeed one of the physicians at the Clinic, while $31.6 \%$ stated that their family physician was elsewhere. In contrast, of those interviewed at FI who had a family physician, only $13.7 \%$ indicated that the physician was at the Westside, and $86.3 \%$ indicated that their physician was elsewhere.

Reasons given for not having a family physician varied. Most respondents indicated that they simply had not been in Saskatoon long enough, while others indicated, as these respondents did, "I haven't been sick at all" or "I don't need one." A few other respondents stated that they simply moved around too much in the city for them to establish a relationship with a particular physician.

\section{Last Visit to Family Physician}

Of those with a family physician, the majority (51.5\%) had seen their family physician within the last month, and almost $75 \%$ had seen their physician within the last three months. Females were more likely to have seen their family physician within the previous one and three month periods than males (82.5\% for females within three months, compared with $68.5 \%$ for males). 
The research indicated that $55.7 \%$ of the Natives, and $44.4 \%$ of the non-Natives had seen their family physician in the last month, and $78.3 \%$ of the Natives and $68.2 \%$ of the non-Natives had seen their family physician in the last three months. It is also interesting to note that while $10.4 \%$ of the Natives indicated that they had seen their family physician "more than a year ago," $17.5 \%$ of the non-Natives indicated likewise. These data would suggest that the Natives in our sample have more contact with their physicians than the non-Natives.

A higher percentage of married males $(50 \%)$ than single males $(40.8 \%)$ had seen their family physician within the last month; and a higher percentage of married females (69.2\%) than single females (58.3\%) had done likewise.

When we control for Native status and marital situation, an interesting observation can be made. Among Native respondents, there is virtually no difference between single and married individuals in terms of having seen their family physician within the last month. Approximately $55 \%$ had done so, regardless of marital status. But for non-Natives, only $33.8 \%$ of single respondents had seen their family physician within the last month, as did $37.5 \%$ of those separated, divorced and widowed, in contrast to $73.3 \%$ of those who were married (these data are statistically significant for non-Natives; chi sq=14.7, $\mathrm{df}=6, \mathrm{sig}=0.023$ ). These data would suggest that marital status for Natives is less important than for non-Natives in terms of actual contact with family physicians.

\section{Last Physical Examination}

Fifty-four percent of the respondents noted having had a physical exam by a physician in the previous year. More females $(61.5 \%)$ than males $(49.2 \%)$ indicated having had a physical exam within the last year (Mann-Whitney $U=5157$, prob $=0.016$ ). Slightly more Natives $(57.0 \%)$ than non-Natives (50.0\%) indicated having had a physical exam in the last year. However, more Natives (12.0\%) than non-Natives (3.6\%) indicated either never having had a physical or else being unable to recall when they last had one.

A higher proportion of Native females $(61.7 \%)$ than males $(50.8 \%)$ reported having had a physical exam within the last year (Mann-Whitney $U=2024, p r o b=0.040$ ); likewise, a higher proportion of non-Native females $(60.0 \%)$ than males $(47.8 \%)$ reported having had a physical, although the data for non-Natives are not statistically significant. 


\section{Perceived Importance of a Family Physician}

The majority of respondents (92\%) stated that having a family physician was important, although more females (95.8\%) than males (89.2\%) felt this way. Also, more respondents with children $(97.8 \%)$ felt that a family physician was important than those without $(88.1 \%)$ (chi $s q=5.82, d f=1, s i g=0.016$ ).

Natives (95.1\%) were more likely to state that a family physician was important than non-Natives (86.9\%). Table 6 summarizes these data.

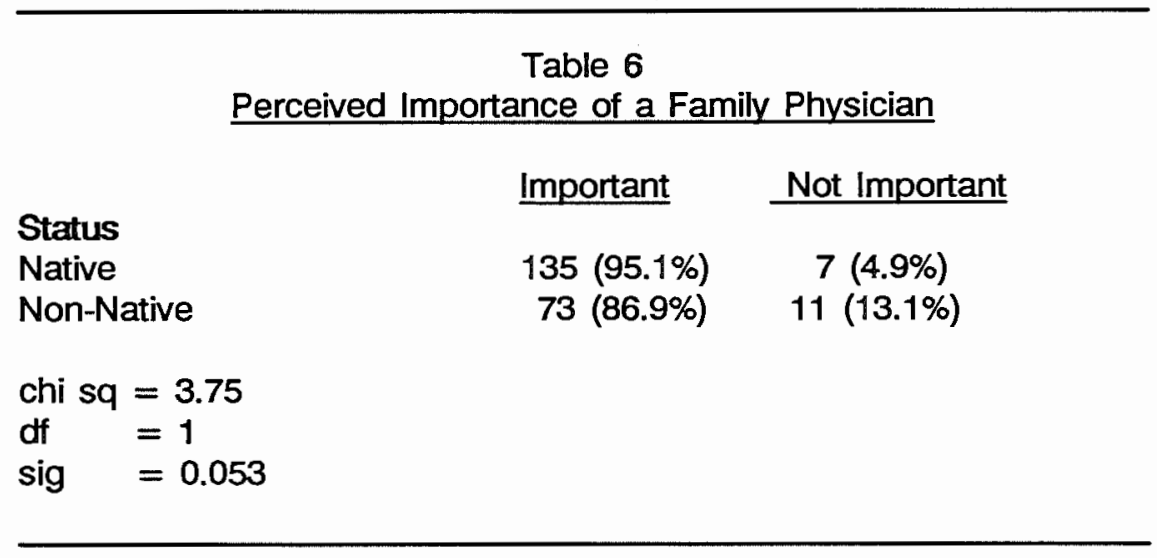

Exploring the question of marital status further, we are able to say that for single individuals, more Natives (96.7\%) than non-Natives (83.3\%) stated that it was important to have a family physician (chi $s q=3.64, d f=1, s i g=0.057$ ). For married individuals, or individuals who were separated, divorced or widowed, there was little difference between Natives and non-Natives.

The presence of children does not seem to be a factor in explaining the differences between Natives and non-Natives in viewing a family physician as important. There was little difference between Native and non-Native respondents that have children, nor was there much difference between Native and non-Native respondents who did not have children.

\section{Hospital Admissions}

For the year prior to the date of the interview, $27.9 \%$ of the respondents indicated that they had been admitted to a hospital at least once. More females (37.5\%) than males $(20.8 \%)$ reported an admission (chi $s q=6.88$, $d f=1, s i g=0.009$ ), although childbirth admissions clearly skew this figure. When we eliminate childbirth cases, only $27.7 \%$ of the females were admitted. There was no significant difference in the mean ages of those reporting an admission and those reporting the contrary. More Natives (33.8\%) were admitted to a hospital than non-Natives (17.9\%) (chi sq=5.9, $\mathrm{df}=1, \mathrm{sig}=0.015$ ), although again the number of Native childbirths obscures the picture. Table 7 presents data for 
hospital admission with childbirth cases deleted, and demonstrates that more Natives were still admitted to hospital.

Natives were more likely to have been admitted to St. Paul's (73.0\%) than non-Natives (38.5\%), and non-Natives showed a greater tendency to be admitted to City and University Hospitals than Natives. These data are presented in Table 8 . In cases where the patients selected the hospital, the main reason was that it was close to their homes, and there is little difference between Natives and non-Natives in this context.

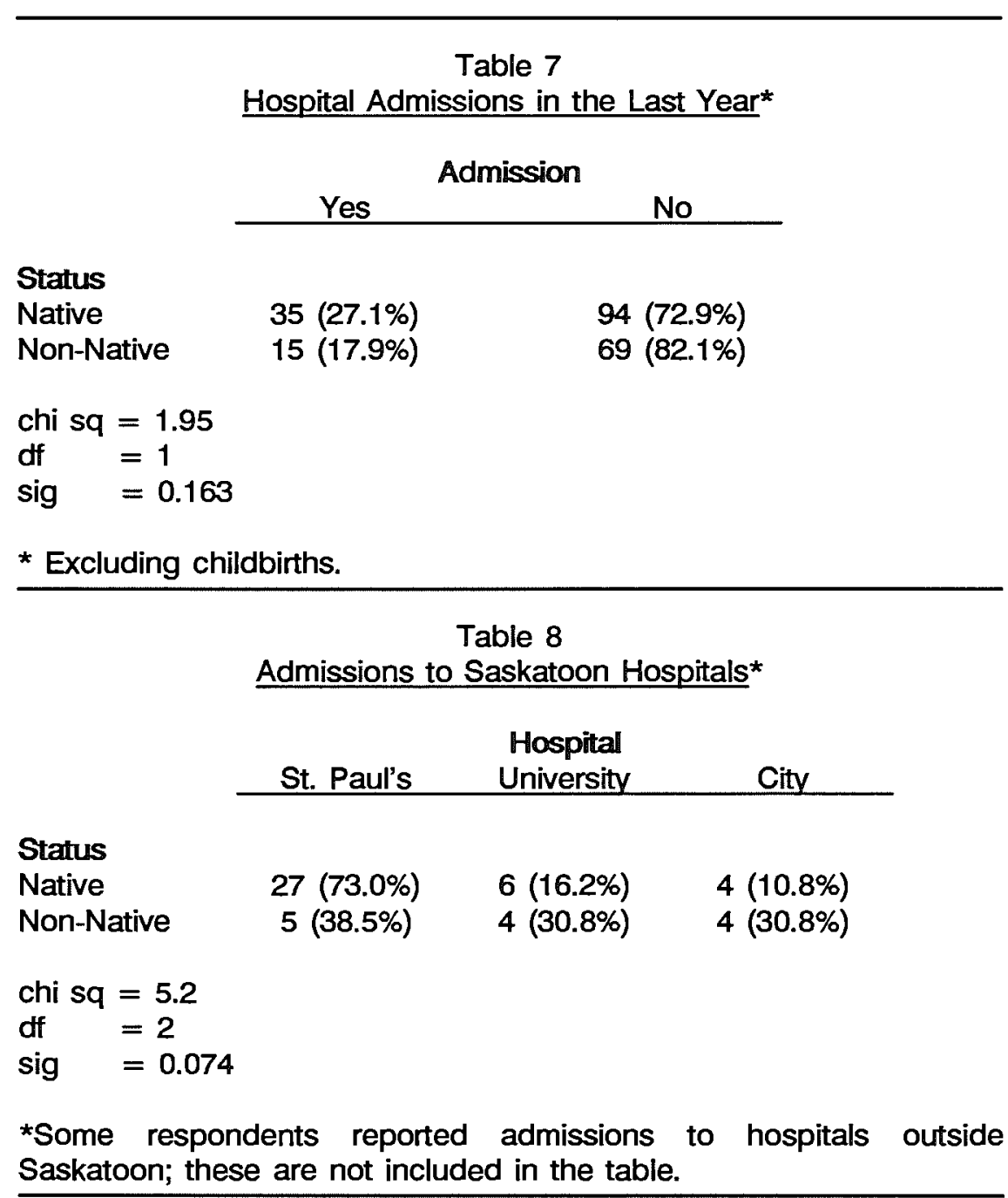

The mean number of hospital admissions for all respondents was 0.416 (this figure includes those who were not admitted); for only those who recorded at least one admission, the mean was 1.49. 
Overall, females tended to have a higher admissions mean $(0.57)$ than males $(0.30)(T=2.16$, $d f=147$, prob $=0.032)$. Natives tended to have a higher admissions mean $(0.55)$ than non-Natives $(0.19)$ $(T=3.57, d f=209, p r o b=0.000)$. This holds true even when we take into consideration hospitalization for childbirth $(T=2.71, d f=43.3$, prob $=0.010)$.

\section{Dental and Visual Health Care}

Overall, only $41.2 \%$ of the respondents reported having seen a dentist in the previous year. There was little difference between Natives and non-Natives, although a higher percentage of Natives (43.0\%) than non-Natives (38.1\%) did report in the affirmative (see Table 9). There was virtually no difference between males and females.

\begin{tabular}{lccc}
\hline & & \multicolumn{3}{c}{$\begin{array}{c}\text { Table 9 } \\
\text { Last Dental Visit }\end{array}$} & \\
& & & \\
\cline { 2 - 4 } & & & \\
Status & & & \\
Native & $61(43.0 \%)$ & $74(52.1 \%)$ & $7(4.9 \%)$ \\
Non-Native & $32(38.1 \%)$ & $51(60.7 \%)$ & $1(1.2 \%)$ \\
chi sq $=3.09$ & & & \\
df $=2$ & & & \\
sig $=0.213$ & & & \\
\hline
\end{tabular}

Only $37.8 \%$ of the respondents reported having a regular dentist, and one quarter of these were unable to provide the dentist's name. More females (42.7\%) than males (34.1\%) indicated that they had a regular dentist, and more females than males were able to name her or him. There was little difference between Natives and non-Natives in having a regular dentist (see Table 10), although slightly more non-Natives than Natives were able to name that person. The age of respondent, number of years in the city, and intra-city mobility did not prove to be significant factors.

\begin{tabular}{lcc}
\hline & \multicolumn{2}{c}{ Table 10 } \\
& \multicolumn{2}{c}{ Respondents with a Regular Dentist } \\
\cline { 2 - 3 } Status & Yes & No \\
\cline { 2 - 3 } Native & $54(38.3 \%)$ & $87(61.7 \%)$ \\
Non-Native & $31(36.9 \%)$ & $53(63.1 \%)$ \\
chi sq $=0.004$, of $=1$, sig $=0.947$ & \\
\hline
\end{tabular}


Overall, 53\% of the respondents reported having had an eye examination within the last two years. More females (59.4\%) than males (48.5\%) reported an eye examination. More Natives (55.6\%) than non-Natives (48.8\%) reported an eye examination (see Table 11 ).

Table 11

Last Eye Examination

Within Last More than 2 Can't Remember/

2 Years Years Ago Never

$\begin{array}{llll}\text { Status } & & & \\ \text { Native } & 79(55.6 \%) & 55(38.7 \%) & 8(5.6 \%) \\ \text { Non-Native } & 41(48.8 \%) & 38(45.2 \%) & 5(6.0 \%) \\ \text { chi sq }=1.015 & & & \\ \text { df } \quad=2 & & & \\ \text { sig } \quad=0.60 & & \end{array}$

\section{Emergency Treatment}

The majority of respondents $(59.9 \%)$ stated that they would go to St. Paul's Hospital for emergency treatment, usually because it was close or because there was something about it that they liked. Interestingly, $11.7 \%$ of the respondents stated that they would go to the WS.

A greater percentage of females $(64.2 \%)$ than males $(56.7 \%)$ indicated that they would go to St. Paul's for emergency treatment. Similarly, a greater percentage of females $(14.7 \%)$ than males (9.4\%) would go to the WS. In contrast, males demonstrated a stronger tendency to use the other hospitals more than the WS. For instance, $11.0 \%$ of the males, compared with $4.2 \%$ of the females, indicated City Hospital, and $11.8 \%$ of the males, compared with $10.5 \%$ of the females, indicated University Hospital.

Marital status is also a factor to be considered here. More single females $(70.0 \%)$ than single males (55.2\%) used St. Paul's Hospital in emergency situations; single males were more likely to use the other two hospitals (chi sq=14.79, $\mathrm{df}=5, \mathrm{sig}=0.01$ ). More married males $(61.3 \%$ ) used St. Paul's than females (54.3\%).

Native respondents were more likely to use St. Paul's Hospital than non-Natives $(70.7 \%$ vs. $41.5 \%$ ), and were more likely to use the WS (14.3\% to $7.3 \%)$. Non-Natives were more likely to use University and City Hospitals, as well as private physicians. 
Overall, $82.2 \%$ of the Natives indicated that they would use one of the three city hospitals in cases of emergency, as compared with $74.5 \%$ of the non-Natives. These data are presented in Table 12. The data for those interviewed at WS, however, demonstrated that both fewer Natives (80.4\%) and non-Natives (71.5\%) would access hospitals in emergency situations compared with the FI respondents (Native, $86.8 \%$; non-Native, $75.4 \%$ ).

Table 12

Choices for Emergency Treatment ${ }^{*}$

\begin{tabular}{|c|c|c|c|c|c|}
\hline & Westside & St. Paul's & $\begin{array}{l}\text { Facility } \\
\text { Private Phys. }\end{array}$ & City Hosp. & Univ. Hosp. \\
\hline Status & & & & & \\
\hline Native & $\begin{array}{c}20 \\
(14.3 \%)\end{array}$ & $\begin{array}{c}99 \\
(70.7 \%)\end{array}$ & $\begin{array}{c}1 \\
(0.7 \%)\end{array}$ & $\begin{array}{c}4 \\
(2.9 \%)\end{array}$ & $\begin{array}{c}12 \\
(8.6 \%)\end{array}$ \\
\hline Non-Native & $\begin{array}{c}6 \\
(7.3 \%)\end{array}$ & $\begin{array}{c}34 \\
(41.5 \%)\end{array}$ & $\begin{array}{c}7 \\
(8.5 \%)\end{array}$ & $\begin{array}{c}14 \\
(17.1 \%)\end{array}$ & $\begin{array}{c}13 \\
(15.9 \%)\end{array}$ \\
\hline
\end{tabular}

chi sq $=38.7$

df $\quad=6$

sig $\quad=0.00$

*Only the major choices are presented.

\section{Utilization of Hospital Emergency Departments (EDs)}

A set of questions was designed to elucidate patterns of voluntary ED utilization, in other words, cases in which individuals made the decision to seek ED treatment either for themselves or for dependents. Episodes of ED utilization where the patient was taken by ambulance or while incapacitated were not included in the analysis.

For the last year, overall $49.8 \%$ of the respondents indicated having gone to an ED for treatment at least once. There is little difference in ED utilization between females and males. Similarly, the age of respondents was not a significant factor.

There was little difference between Natives and non-Natives concerning having gone to an ED in the last year. Some $51 \%$ of the Native respondents had gone to an ED at least once, compared with $47.6 \%$ of the non-Natives (see Table 13). Natives registered a higher mean number of ED visits in the last year (1.35) compared with non-Natives (0.96). 


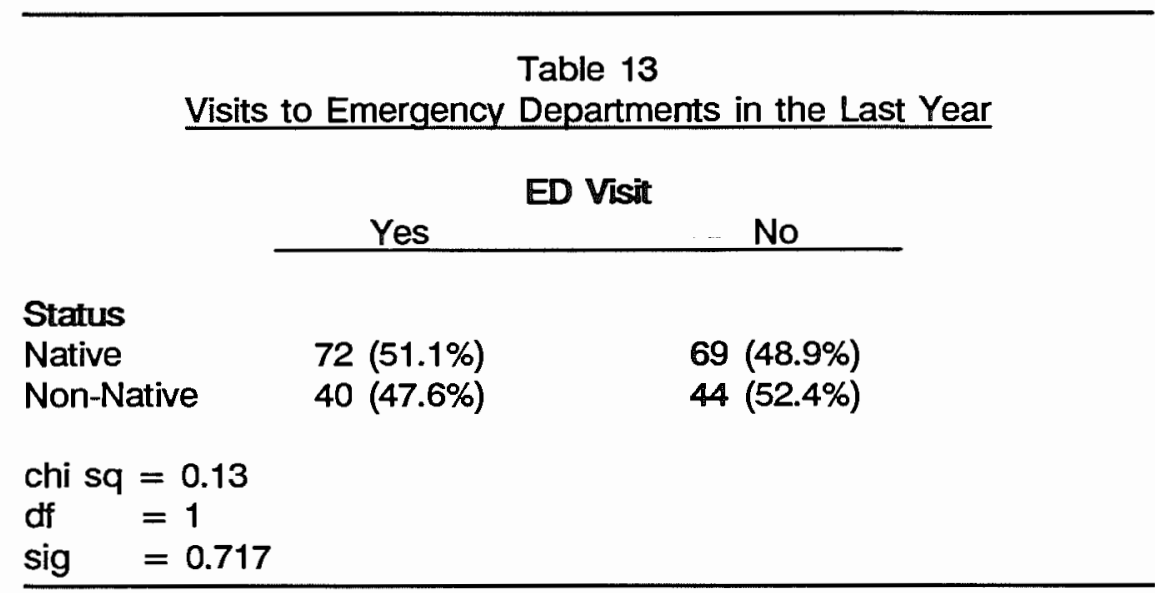

Intra-city mobility may be an important factor in understanding ED utilization. For individuals reporting only one residence in the previous year, $40.7 \%$ had visited the ED at least once during that year. For individuals with two residences, $65.5 \%$ reported a visit, and for individuals with three or more residences, $50.8 \%$ reported at least one visit (Mann-Whitney $U=5481$; prob $=0.061$ ). There is also a mild relationship between the number of places a person has lived in the city in the last year and the number of times that person sought treatment at the ED $(r=.289, p=0.000)$. This suggests that the more places a person has lived in the city, the greater the number of times they used the ED.

Most respondents (58.1\%) selected the ED on the grounds that it was closest to them. The vast majority of Natives went to St. Paul's ( $89.9 \%$, compared with $43.6 \%$ for non-Natives). Non-Natives were more likely to go to University and City Hospitals than were Natives (chi $s q=27.9, \mathrm{df}=2$, $\mathrm{sig}=0.000$ ). Furthermore, Natives tended to select the ED primarily on the grounds that it was closest to their homes $(70.1 \%$, compared with $36.8 \%$ for non-Natives) while non-Natives had more varied reasons, especially because a particular physician had privileges there (chi $s q=18.76, \mathrm{df}=3, \mathrm{sig}=0.003$ ). This could indicate the extent to which convenience is an important factor in Native health care seeking behaviour. When we look at the spatial distribution of the respondents, we see that a higher proportion of Natives (66.5\%) were living in the residential areas closest to St. Paul's (Mount Royal, Westmount, Riversdale, Pleasant Hill, Meadow Green) as compared with non-Natives (52.4\%). Furthermore, more non-Natives (16.7\%) than Natives $(7.1 \%)$ lived on the east side of the river, and more non-Natives (13.1\%) than Natives (4.3\%) lived in the "downtown" area east of Idylwyld Drive or in City Park.

Most ED visits (49.1\%) occurred during the day, defined as between 6:00 a.m. and 6:00 p.m., followed by evening (36.8\%) (6.01 p.m. to midnight) and nighttime (14.1\%) (12:01 a.m. to 5:59 a.m.). Hence, we can say that about half of the ED visits occurred during the period in which other medical facilities (such as physicians' offices and clinics) were likely open. Non-Natives showed a greater 
tendency to visit the ED during the daytime (55.3\%) in comparison with Natives (45.6\%). Summary data are presented in Table 14.

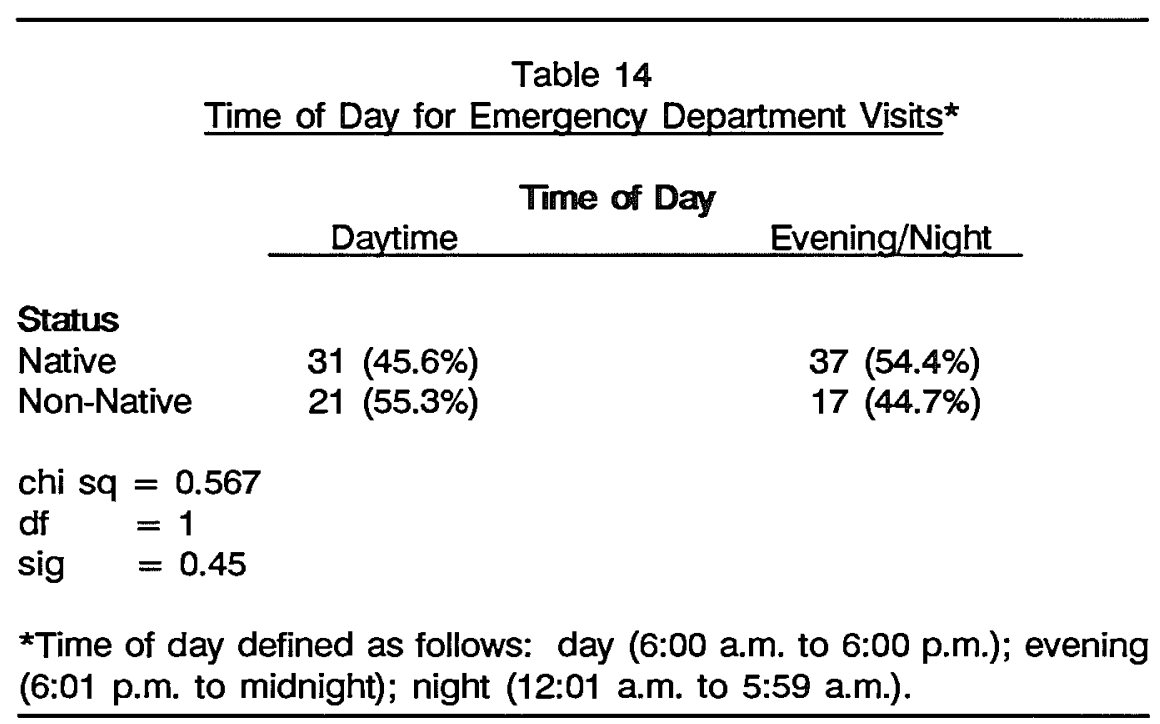

It is also interesting to note that, for those who had lived in one place only and who had gone to an ED, 51.3\% had done so during the daytime; this compares with 57.9 percent of those who had lived in two places, and $34.5 \%$ of those who had lived in three or more places. Hence, the more mobile individuals are not necessarily those utilizing the ED during hours when other facilities might be available.

There is an interesting observation in terms of the number of years a person has lived in the city and whether or not they had visited an ED; for those in the city less than one year, $38.6 \%$ had visited an ED; for those in the city between one and five years, $62.3 \%$ had visited an ED; and for those in the city more than five years, $48.4 \%$ had visited an ED (Mann-Whitney $U=6245, p r o b=0.850$ ). These data suggest that length of time in the city is not an important factor in reducing ED visits, and indeed it appears as though longer term residents are more likely to use the ED than shorter term residents. However, there was no relationship between the number of years in the city and the number of times a person visited an ED.

A commonly held view within the medical establishment is that many people, especially Natives, visit hospital emergency departments for non-emergency medical problems, in other words, for problems which could await an appointment with a physician. Concerning their most recent ED visit, in almost every case respondents went to the EDs because they believed that their problem, or that of their dependents, required the immediate attention of a physician (95.3\%). However, in most cases (85.5\%) 
they were treated and released. There is obviously a discrepancy in attitude regarding the severity of medical problems between clients and medical practitioners. There were few differences between Natives and non-Natives on these variables.

Data were collected for the three most recent ED visits (if appropriate) by respondents. A total of 175 visits was recorded, with Natives accounting for $72 \%$, which is slightly higher than their proportion in the overall research (where Native respondents accounted for $62.8 \%$ of the respondents). While some respondents reported more than three visits, data were not gathered on these.

Traumatic injuries caused by accidents, violence and poisoning are a significant cause of voluntary visits to EDs. In this research, it is interesting to note that for both Native and non-Natives, $38.8 \%$ of the ED visits were due to such causes. These causes reflect the unique lifestyle of the urban poor, and the data would suggest that race or ethnicity is not a relevant factor. Unfortunately, comparable data for ED visits by more affluent urban dwellers are unavailable, and hence we cannot say to what extent individuals in our sample might make a greater or smaller number of ED visits as a result of accidents, violence or poisoning.

\section{Utilization of Medi-Clinics}

Medi-clinics, or drop-in medical facilities, are generally characterized by their extended hours and their willingness to treat individuals without appointments. They were not used extensively by respondents in this study. Only $\mathbf{2 3 . 6 \%}$ indicated that they had visited one at least once in the previous year. There exists little difference between Natives and non-Natives concerning having visited a medi-clinic at least once in the last year. Similarly, there is little difference in terms of the mean number of visits in the last year. The mean number of visits to a medi-clinic was 3.8 for those who recorded at least one visit in the last year. The Native mean was 4.1, and the non-Native mean was 3.3.

There are in fact no medi-clinics in the west core area of the city, although a few do exist as one moves even further west into the suburbs, and especially the Confederation Park area which has a fairly high number of Native residents. But this area is quite distant from the research site. It is significant that both the Westside Clinic and the Emergency Department at St. Paul's Hospital act, in effect, as drop-in medi-clinics, with the hospital actually open twenty-four hours daily. Therefore, while medi-clinics per se were not utilized extensively, institutions operating in a similar manner were in fact the most utilized health care institutions in the study area. 


\section{Onset of Symptoms}

Respondents at the WS were asked when they first noticed the symptoms of the particular problem which brought them to the Clinic on the day of their interview. Only those with acute and recent conditions were considered here. The mean number of days which lapsed between symptom onset and first medical consultation was 3.9 days. There exists some difference between Natives and non-Natives on this variable, with Natives recording a mean of 3.8, and non-Natives a mean of 5.0 days (the difference is not statistically significant, however).

There did exist a strong relationship between the number of places a person had lived in the last year and the time lapse before seeking treatment $(r=.4085, p=.001)$. This would suggest that individuals who are more mobile within the city tend to wait longer before consulting a physician or nurse for a health problem.

\section{RELATED PROBLEMS IN HEALTH CARE UTILATION \\ Clinical Communication Problems}

A series of questions was designed to determine the kinds of communication problems encountered by respondents in accessing and utilizing urban health care facilities. In general, the literature has suggested that communication problems are extensive among urban Native residents, and may be both cultural and linguistic in nature.

Overall, only $23.9 \%$ of the respondents reported ever having difficulty explaining their health problem to a physician or nurse. More Natives (26.1\%) than non-Natives $(20.2 \%)$ reported such problems. Among the Native respondents, $29.3 \%$ of those who indicated speaking an Indian language today stated that they have difficulties explaining their health problem to a physician or nurse, in contrast to $16.3 \%$ of those who do not currently speak an Indian language. While in general the age of the respondent was not a relevant factor, the mean age of those Natives expressing difficulty in this area was higher (33.1) than for those Natives not having such a difficulty (29.8).

From the interviews it was clear that many of those who indicated having difficulty explaining their health problem either had difficulty with the English language ("I couldn't find the right words [in English] to explain what was wrong") or else were embarrassed to discuss their problem with the physician. The latter generally referred to situations where a female was consulting a male physician for "female problems."

Some $39 \%$ of the respondents also reported having difficulty understanding the medical language or vocabulary used by a physician or nurse. More Native respondents $(43.3 \%)$ than nonNatives $(32.1 \%)$ reported having problems (see Table 15 ). 
Table 15

Problems Understanding Medical Language

Status

Native

Non-Native

\begin{tabular}{rr} 
Res & Noprting a Problem \\
\hline
\end{tabular}

chi $s q=2.29$, of $=1$, sig $=0.131$

$80(56.7 \%)$

$57(67.9 \%)$

A higher percentage of Natives with an Indian language as a first language (45.6\%) reported such difficulties, compared with those whose first language was English or French (35.8\%). Among Natives speaking an Indian language today, $45.5 \%$ expressed problems understanding the language used by a physician, as compared with $35.7 \%$ of the non-Indian language speakers. The primary problem reported by respondents was the view that physicians used "big words" without explanation.

Overall, $19 \%$ of the respondents reported having difficulties understanding a physician's instructions to them concerning a health problem. More Natives (23.2\%) than non-Natives (11.9\%) indicated such problems (chi $s q=3.69, \mathrm{df}=1, \mathrm{sig}=0.055$ ) (see Table 16). There was little difference between those Natives still speaking an Indian language and those who do not in terms of understanding a physician's instructions. Problems ranged from not understanding the English or the "big words" to the view that physicians do not usually explain what is wrong with the patient, or why certain medication is necessary.

Table 16

Problems Understanding a Physician's Instructions

\begin{tabular}{lrr} 
& \multicolumn{2}{c}{ Reporting a Problem } \\
\cline { 2 - 3 } & \multicolumn{3}{c}{ Yes } \\
Status & $33(23.2 \%)$ & $109(76.8 \%)$ \\
Native & $74(88.1 \%)$ \\
Non-Native $\quad 10(11.9 \%)$ & \\
chi $s q=3.696$, df $=1$, sig $=0.055$ &
\end{tabular}


Only $14.2 \%$ of the respondents indicated problems understanding a physician's instructions for taking a prescribed medicine. There is little difference between Natives and non-Natives. Similarly, there was little difference between current Indian and non-Indian language speakers.

\section{Pharmacy Utilization}

Almost $70 \%$ of the respondents reported having a regular pharmacy that they used for their medical needs, and virtually all of these could name or describe the location of the pharmacy. There was little difference between Natives and non-Natives. More females (76.0\%) than males (64.6\%) reported having a regular pharmacy.

The number of years in which a person had lived in the city seems to be a factor in understanding the existence of a regular pharmacy. Of those in the city one year or less, $56.8 \%$ reported having a regular pharmacy; of those in the city between one and five years, $66.0 \%$ reported likewise, as did $75.2 \%$ of those in the city for more than five years (Mann-Whitney $U=4474$, prob=0.019).

\section{Paying for Prescription Drugs}

Almost a quarter of the respondents $(24.8 \%)$ reported having problems paying for prescription drugs. Fewer Natives (20.4\%) related problems in this area than non-Natives (32.1\%), although the fact that status Indians receive free prescriptions is an important factor. For the non-Natives, the non-status Indians and the Métis, the impact of Saskatchewan's new drug policy is likely minimal in this study, which was undertaken around the time of its introduction. This policy altered the method of payment for prescription drugs, and required consumers to pay initially for the total cost of a drug, with some reimbursement to be forthcoming if their total prescription drug expenditures for the year exceeded a pre-established limit.

\section{Paying for Non-Prescription Medicines}

Overall, $30.1 \%$ of the respondents reported problems paying for non-prescription medicines. There was a significant difference between Natives and non-Natives (chi sq=4.13, df=1, sig=0.042), with $35.2 \%$ of the Natives and $21.4 \%$ of the non-Natives reporting problems. Furthermore, more females $(42.7 \%)$ than males $(20.8 \%)$ reported such problems (chi $s q=11.61$, $d f=1, s i g=0.00$ ). 


\section{Medicine Literacy}

A series of four questions was designed to determine the existence of literacy problems in the utilization of medicines. A bottle of "Triaminic Decongestant Cold Syrup" (non-prescription) was shown to each respondent, and each was asked to read the label and directions and identify the medicine and its uses.

Overall, only $27.4 \%$ of the respondents were able to identify the medicine specifically as a "decongestant;" fewer Natives (23.9\%) than non-Natives (33.3\%) were correct (see Table 17). There was little difference between Natives currently speaking an Indian language in addition to English, and those who did not. However, fewer of those with an Indian language as their first language (18.2\%) than those with a non-Indian first language (32.3\%) were able to identify the medicine (chi sq=4.25, $\mathrm{df}=1$, sig=0.039).

\begin{tabular}{lcr}
\hline & $\begin{array}{c}\text { Table 17 } \\
\text { Medicine Identification }\end{array}$ \\
\cline { 2 - 3 } & \multicolumn{2}{c}{$\begin{array}{c}\text { Accurate Identification } \\
\text { Yes }\end{array}$} \\
Status & & \\
Native & $33(23.9 \%)$ & $105(76.1 \%)$ \\
Non-Native & $27(33.3 \%)$ & $54(66.7 \%)$ \\
chi sq $=1.828$ & & \\
df $\quad=1$ & & \\
sig $=0.176$ & & \\
&
\end{tabular}

It should also be noted that there was a relationship between the level of education and ability to identify the medicine. The mean number of years completed at school for those identifying the medicine was 10.4 , compared with 8.7 for those unable to identify it $(T=5.04, d f=217, p r o b=0.00)$.

Only $23.9 \%$ of the respondents were able to identify specifically what the medicine was to be used for, and a further $41.7 \%$ could state only that it was used for "colds" without being more specific. Fewer Natives $(21.2 \%)$ than non-Natives $(28.4 \%)$ were able to specifically identify its usage. There was no significant difference between Natives who still speak an Indian language and those who do not.

Overall, $74.3 \%$ of the respondents were able to report the correct dosage to be taken. More non-Natives $(79.0 \%)$ than Natives $(71.5 \%)$ were able to give the correct response. Only $63.2 \%$ of those Natives with an Indian language as their first language were able to report the correct dose, compared 
with $78.9 \%$ of those with a non-Indian first language. Furthermore, while $\mathbf{2 8 . 9} \%$ of the Indian first language speakers gave the incorrect dose (and a total of $36.8 \%$ were either incorrect or unable to respond), only $16.5 \%$ of the non-Indian language speakers did likewise (and only $21 \%$ were either incorrect or unable to respond). These data are presented in Table 18. There was little difference between Natives who currently speak an Indian language and those who do not in accurately identifying the dosage.

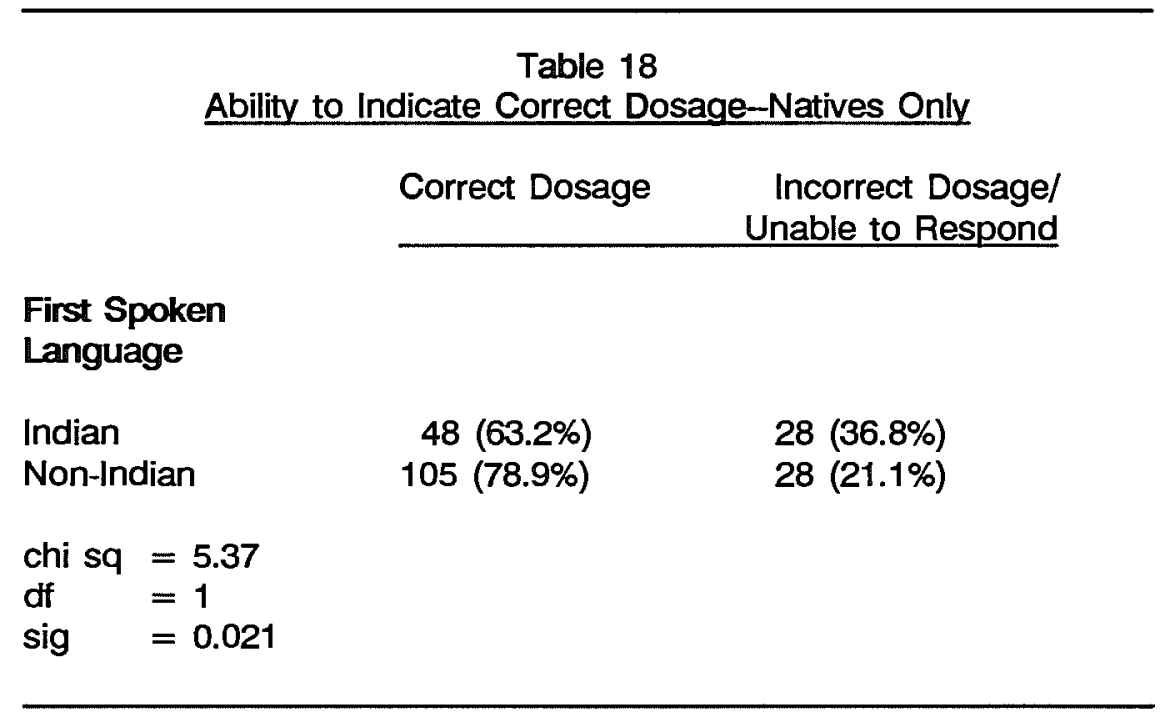

There did exist a difference in educational levels, with those identifying the correct dosage having a mean formal education of 9.4 years, compared with 8.3 years for those incorrect or unable to respond $(\mathrm{T}=2.9, \mathrm{df}=216$, prob=0.004).

Overall, $71.1 \%$ of the respondents were able to report the correct frequency for taking the medicine, and hence almost $30 \%$ were unable to do so. Fewer Natives (68.6\%) than non-Natives (75.3\%) were able to report the correct frequency.

Of those speaking an Indian language as a first language, $64.5 \%$ gave the correct frequency, compared with $75.9 \%$ of those with a non-Indian language. There was a significant difference between Natives who spoke an Indian language and those who did not. Among those currently speaking an Indian language, a total of $34.7 \%$ either stated the incorrect frequency or were unable to offer any comment ("I don't know"), compared with $23.8 \%$ of those not speaking an Indian language (chi sq=9.82, $\mathrm{df}=2$, sig=0.01). 
Those able to identify the frequency correctly tended to have a higher educational level (mean= 9.6 years) compared with those who were unable to identify the frequency (mean=8.2 years) $(T=3.99$, $d f=216$, prob $=0.00$ ).

\section{Transportation}

Overall, $34.5 \%$ of the respondents reported having difficulties travelling to see a physician or nurse. There exists a significant difference between Natives and non-Natives (chi $s q=4.7, d f=1$, sig $=0.03$ ), with $40.1 \%$ of the Natives and only $25 \%$ of the non-Natives reporting such problems. Furthermore, females have significantly more problems than males (chi $s q=14.32, d f=1, s i g=0.00$ ), with $49 \%$ of the females and only $23.8 \%$ of the males reporting transportation problems. Many of the problems for the females related to the need to take children along with them to the physician's office.

There exists a significant difference between those with an Indian language as a first language and those with another language. Among Indian first language speakers, $45.6 \%$ reported transportation difficulties; among non-Indian first language speakers, the figure was $28.1 \%$ (chi $s q=5.94, d f=1$, sig=0.015). Furthermore, among Natives, $44.4 \%$ of those who speak an Indian language today indicated such problems, compared with $27.9 \%$ of the non-Indian language speakers. Transportation problems varied, but many reported the difficulties they encountered in taking the bus ("It's hard travelling by bus with kids"), and the costs of bus or taxi fare.

\section{Making Appointments}

Overall, only $18.1 \%$ of the respondents reported having difficulty making appointments. There was little difference between Natives and non-Natives. More females $(24 \%)$ than males (14\%) indicated problems in this area.

The difficulties expressed included the lack of a personal phone to call physicians' offices and the likelihood that the respondent would be unable to see the physician immediately. Later, this report examines the question of appointments in greater detail.

\section{Babysitting}

Overall, only $13.7 \%$ of the respondents reported having difficulty finding a babysitter so that they could go for medical treatment. However, the Native respondents clearly have more difficulty, in part due to the fact that there were more females and families among the Native sample. While $20.7 \%$ of the Natives reported having problems finding a sitter, only $2.4 \%$ of the non-Natives had such problems (chi $s q=13.25$, df $=1$, sig=0.00). Significantly more females $(29.3 \%)$ than males $(2.4 \%)$ indicated such 
problems (chi sq=30.62, $\mathrm{df}=1, \mathrm{sig}=0.00$ ). Native females in particular expressed a difficulty, with $33.8 \%$ explaining that babysitting was a problem.

Natives (20\%) also reported having problems paying for babysitters to a greater extent than non-Natives $(7.2 \%$ ) (chi sq=5.57, $\mathrm{df}=1, \mathrm{sig}=0.02$ ). Similarly, more females $(30.1 \%)$ than males $(4.0 \%)$ reported such financial problems (chi $s q=26.29, \mathrm{df}=1$, sig $=0.00$ ).

\section{UTUZATION OF THE WESTSIDE CLNIC}

A series of questions was designed to elicit information from WS patients concerning their utilization of the Clinic. The following data provide greater insight into the utilization of this particular health care facility.

\section{Assessing and Utilizing the West Side Clinic}

Overall, most respondents first heard of the WS Clinic from a friend or member of their family (56.6\%), followed by simply seeing it as they travelled by (19.7\%). There is little difference between Natives and non-Natives, although more Natives $(62.7 \%)$ than non-Natives $(50.0 \%)$ were told about the Clinic by someone else.

Most (56.5\%) patients walked to the Clinic on the day of their interview, followed by personal automobile (18.5\%) and bus (13.7\%). However, there was a significant difference between Natives and non-Natives, with $57.1 \%$ of the non-Natives using a personal automobile, compared with $10.7 \%$ of the Natives, and $62.1 \%$ of the Natives walking, compared with $28.6 \%$ of the non-Natives (chi sq $=\mathbf{2 5 . 5 1}$, $\mathrm{df}=4$, sig=0.00). More females $(16.3 \%)$ than males took the bus, and more females $(10.0 \%)$ than males (2.3\%) "got a ride," perhaps reflecting the problems of transporting children to the Clinic.

Overall, $85 \%$ of those interviewed at WS had been to the Clinic before for medical treatment. There was little difference between Natives and non-Natives. There was, however, a difference between males and females, with $92.6 \%$ of the females reporting having been to the Clinic before, compared with $72.7 \%$ of the males (chi $s q=7.59, d f=1, s i g=0.01$ ). Seventy-six percent of the respondents at WS stated that the Clinic was the place that they "usually" went for medical treatment. There was little difference between Natives and non-Natives. Significantly more females (82.7\%) than males (64.3\%) stated that they used the Clinic regularly (chi sq $=4.24, \mathrm{df}=1$, sig=0.04).

Patients frequently arrived at the Clinic accompanied by another individual. Overall, $36.3 \%$ of the respondents interviewed came to the Clinic to consult for a personal medical problem, $15 \%$ came with someone who was to see the physician (often a child), and $48.7 \%$ came both for themselves and for someone else (again, often a child). Interestingly, 33.1\% of the Natives came for both themselves 
and someone else, compared with $75 \%$ of the non-Natives (chi $s q=40.17, \mathrm{df}=2, \mathrm{sig}=0.000$ ). Almost $45 \%$ of the Natives came only for themselves, compared with only $22.6 \%$ of the non-Natives. There is also a difference between the sexes. Most females (54.2\%) came only for themselves, while most males (66.9\%) came both for themselves and for others (chi $s q=40.83, d f=2, s i g=0.00$ ).

In general, respondents selected the Westside Clinic either because of a particular physician with whom they wished to consult $(38.1 \%)$ or because the Clinic was close to where they lived (34.7\%). There is a significant difference between Natives and non-Natives (chi $s q=7.52, \mathrm{df}=3$, sig=0.057), with many more Natives coming to WS because it was close $(37.8 \%)$ than non-Natives $(20 \%)$ and many more non-Natives coming because of a particular physician (65\%) than Natives (32\%). Combined with the data on how the respondents travelled to the Clinic, these data would suggest that convenience is clearly a greater factor for the Native respondents than it is for the non-Native respondents.

The vast majority $(92.6 \%)$ of the respondents indicated that they would return to the Clinic for future health care needs, and there was little difference between the Natives and the non-Natives. The main reason cited for returning was to see a particular physician (36.6\%), followed by the fact that the Clinic was close $(25.9 \%)$ and that the respondent liked it $(25.0 \%)$. Again we can note that more non-Natives (50.0\%) than Natives (33.7\%) gave a particular physician as the reason they would return, while more Natives (28.3\%) than non-Natives (15.0\%) explained that the closeness of the Clinic was the key reason.

\section{Appointments and Drop-lns}

An examination of the Clinic's day sheets revealed that $43.3 \%$ of the patients seen during the period in which this research was undertaken did not have an appointment. They were, in other words, "drop-ins." This figure does not include potential patients who, not having appointments, were turned away (at least temporarily) because there were no openings (we are led to believe that these were few in number). Of the $56.7 \%$ of those patients who had made appointments, a minority but undetermined number failed to show.

For those individuals who were interviewed as part of this research, $62.4 \%$ had arrived at the Clinic without appointments on the day they were interviewed. The data reveal a clear relationship between the existence of a personal telephone in the home, or access to one, and the likelihood that an individual had made an appointment. Approximately 59\% of those with telephones had made appointments, compared with $31.9 \%$ of those without phones (chi $s q=4.78, d f=1, s i g=0.03$ ). While some individuals made appointments in person, appointment-making is most frequently done over the telephone. The data also revealed that only $29.1 \%$ of the Native respondents had phones, compared 
with $82.4 \%$ of the non-Natives (chi $s q=14.57, \mathrm{df}=1$, sig=0.00). Hence, it is not surprising that only $33.3 \%$ of the Natives interviewed had made appointments, in contrast to $58.8 \%$ of the non-Natives (chi $s q=2.9, \mathrm{df}=1$, sig=0.088).

\section{The Impact of the Westside Clinic}

One of the main reasons for the establishment of the Westside Clinic was to provide health care in an area recognized as being underserved, thereby attracting patients away from the Emergency Department at St. Paul's Hospital. The data allow for a partial assessment of the impact of the Westside Clinic on health care utilization patterns in the west core area through a comparison of those utilizing the Clinic with those utilizing other facilities. Analyses on two indices are particularly relevant: the regular source of an individual's non-emergency care, and the location of the individual's regular or family physician (where so indicated.)

As noted previously, respondents were requested to indicate where they normally went for non-emergency health care. By combining categories we can group those who indicated the WS, and all others who indicated some other facility or individual. There proved to be little difference between the WS users and those using other facilities or services in terms of the existence of a family physician: $76.7 \%$ of the WS users, and $78.8 \%$ of the users of other facilities indicated having a family physician (see Table 19). Similarly, there was little difference between the two groups in terms of recognizing the importance of having a family physician (94.9\% of the WS users, and $89.5 \%$ of the users of other facilities so indicated). However, considerably more WS users had seen their family physicians recently in comparison with users of other facilities. Table 20 summarizes these data. Separating these data for Natives and non-Natives, we see that $80.6 \%$ of the Natives who use the WS regularly had seen their physician in the last three months, in comparison with $73.0 \%$ of the Natives who regularly use another facility. In contrast, while $100 \%$ of the non-Natives who regularly use the WS indicated having seen their physician within the last three months, only $54.6 \%$ of the non-Native users of other facilities reported the same. 
Table 19

Respondents with Regular or Family Physician

Regular Source of Non-Emergency Care

Westside

Elsewhere

chi $s q=0.047$

df $=1$

sig $=0.829$

Table 20

Last Visit to Family Physician

\begin{tabular}{clcc}
$\begin{array}{c}\text { Within Last } \\
\text { Month }\end{array}$ & $\begin{array}{l}\text { Within Last } \\
\text { Three Months }\end{array}$ Within Last & More Than & One Year \\
\hline
\end{tabular}

Reg. Source Family Physician

of Non-Emerg.

Care

$89(76.7 \%) \quad 27(23.3 \%)$

$82(78.8 \%) \quad 22(21.2 \%)$

$\begin{array}{lcccc}\text { Westside } & 51(60.7 \%) & 20(23.8 \%) & 6(7.1 \%) & 7(8.3 \%) \\ \text { Elsewhere } & 34(42.0 \%) & 17(21.0 \%) & 15(18.5 \%) & 15(18.5 \%)\end{array}$

Mann-Whitney $U=258$, prob $=.004$

The impact of the WS is also noticeable when we examine the utilization of hospital emergency departments. A slightly higher percentage of regular WS users $(53.8 \%)$ reported at least one visit to an ED in the previous year compared with users of other facilities (45.7\%), and this observation holds for both Native and non-Native respondents. However, $55.7 \%$ of the WS users made such a visit in the evening or at night when most other facilities (including the WS) were likely closed. This compares with $45.5 \%$ of the individuals who regularly used facilities other than the WS (see Table 21). 
Table 21

Time of Day For ED Visits

\begin{tabular}{|c|c|c|}
\hline $\begin{array}{l}\text { Regular Source } \\
\text { of Non-Emergenc }\end{array}$ & Time of Day & \\
\hline Care & Daytime & Evening/Night \\
\hline Westside & $27(44.3 \%)$ & $34(55.7 \%)$ \\
\hline $\begin{array}{l}\text { Elsewhere } \\
\begin{aligned} \text { chi sq } & =0.709 \\
\text { df } & =1 \\
\text { sig } \quad & =0.29\end{aligned}\end{array}$ & $24(54.5 \%)$ & $20(45.5 \%)$ \\
\hline
\end{tabular}

These data are even more striking when we examine the utilization patterns of Natives and non-Natives separately. For Natives, $37.5 \%$ of the regular Westside users who visited the ED did so during the daytime, in comparison with $65.0 \%$ of the Native users of other facilities (Table 22). In contrast, $69.2 \%$ of the non-Native Westside users, and $45.8 \%$ of the non-Native users of other facilities who visited an ED did so during the daytime (Table 23). Hence we can say that regular Native WS users tended to use the ED less during periods of the day in which other facilities were available, while non-Natives overall tended to use ED services more during the daytime. The Westside's impact in this area has been greater for the Natives.

Table 22

Time of Day for Native ED Visits

\begin{tabular}{|c|c|c|}
\hline \multirow{2}{*}{$\begin{array}{l}\text { Regular Source of } \\
\text { of Non-Emergency } \\
\text { Care }\end{array}$} & \multicolumn{2}{|c|}{ Time of Day } \\
\hline & Daytime & Evening/Night \\
\hline Westside & $18(37.5 \%)$ & $30(62.5 \%)$ \\
\hline $\begin{array}{l}\text { Elsewhere } \\
\begin{aligned} & \text { chi sq }=3.27 \\
& \text { df }=1 \\
& \text { sig } \quad=0.071\end{aligned}\end{array}$ & $13(65.0 \%)$ & 7 (35.0\%) \\
\hline
\end{tabular}


Table 23

Time of Day for Non-Native ED Visits

\section{Regular Source of Non-Emergency} Care

Westside

Elsewhere

chi sq $=1.04$

df $=1$

sig $\quad=0.309$
Time of Day

Daytime Evening/Night

$\begin{array}{cr}9(69.2 \%) & 4(30.8 \%) \\ 11(45.8 \%) & 13(54.2 \%)\end{array}$

Another comparison can be made by examining the data in terms of the location of regular or family physicians, where so indicated by the respondent. The commitment to the WS by those who perceived a WS physician to be their regular physician was understandably strong, with $90.7 \%$ of those with a WS physician indicating that the WS was where they normally went for non-emergency treatment. Interestingly, $34.8 \%$ of the Natives who reported a regular physician located elsewhere nonetheless stated that the WS was where they normally went for treatment (such was not the case for the non-Natives, who demonstrated a strong loyalty to their regular physicians). The WS thus appears to be attracting patients from other practitioners. As well, those with WS physicians indicated having seen that physician more recently than those utilizing physicians based elsewhere. Table 24 summarizes these data. This observation is particularly true for the Native respondents: $86.8 \%$ who reported a WS physician as their regular or family physician also reported having seen that physician within the last three months, in comparison with $69.7 \%$ of those Natives utilizing physicians located elsewhere. In contrast, while $100 \%$ of the non-Natives with WS physicians reported a consultation within the last three months, only $58.7 \%$ of the non-Natives who identified a regular physician from elsewhere did likewise. Tables 25 and 26 summarize these data. 
Table 24

Last Visit to Family Physician

Location of

Last Visit

Family

Physician

Within Last Within Last Within Last More Than Month Three Months Year Year Ago

Westside $48(70.6 \%)$

$13(19.1 \%)$

$5(7.4 \%)$

$2(2.9 \%)$

Elsewhere

$36(39.1 \%)$

$23(25.0 \%)$

$14(15.2 \%) \quad 19(20.7 \%)$

Mann-Whitney $U=1976$, prob $=0.000$

Table 25

Last Visit to Family Physician by Native Respondents

Location of

Family

Physician

Westside

Elsewhere

\section{Last Visit}

\begin{tabular}{cccc}
$\begin{array}{c}\text { Within Last } \\
\text { Month }\end{array}$ & $\begin{array}{c}\text { Within Last } \\
\text { Three Months }\end{array}$ & $\begin{array}{c}\text { Within Last } \\
\text { Year }\end{array}$ & $\begin{array}{l}\text { More Than } \\
\text { Year Ago }\end{array}$ \\
\hline
\end{tabular}

$\begin{array}{lrll}37(69.8 \%) & 9(17.0 \%) & 5(9.4 \%) & 2(3.8 \%) \\ 20(43.5 \%) & 12(26.1 \%) & 6(13.0 \%) & 8(17.4 \%)\end{array}$

Mann-Whitney $\mathrm{U}=863$, prob $=0.005$
Table 26

Last Visit to Family Physician by Non-Native Respondents

Location of

Family

Physician

Within Last
Month

Westside

Elsewhere
Last Visit

Within Last Three Months

$4(26.7 \%)$

$11(23.9 \%)$
$16(34.8 \%)$

Mann-Whitney $U=294$, prob $=0.002$

There was some difference in terms of having visited a hospital ED in the previous year, as Table 27 indicates. The data reveal that $49.2 \%$ of the Natives who regularly use a WS physician reported a visit to an ED, in comparison with $59.6 \%$ of the Natives who use a physician located elsewhere. Similarly, $50.0 \%$ of the non-Natives with a WS physician, and $58.7 \%$ of the non-Natives with 
a physician elsewhere reported a visit to the ED. Hence we can say that the WS appears to have some success in deflecting potential patients from hospital emergency departments, whether or not they are Native.

Table 27

Visits to Hospital Emergency Departments in Last Year

\begin{tabular}{llc}
$\begin{array}{l}\text { Location of } \\
\text { Family } \\
\text { Physician }\end{array}$ & \multicolumn{2}{c}{ Visit to ED } \\
& Yes & No \\
\cline { 2 - 3 } Westside & $37(49.3 \%)$ & $38(50.7 \%)$ \\
Elsewhere & $55(59.1 \%)$ & $38(40.9 \%)$
\end{tabular}

chi $s q=1.28, \mathrm{df}=1, \mathrm{sig}=0.265$

In examining communication problems, it is best to offer comparisons for the Native respondents only, since they indicated significantly more communication problems than the non-Natives. In so doing, we see that there were few significant differences between those who regularly utilize the WS and/or have regular physicians there, and those who utilize other individuals or facilities. For instance, in terms of reported problems understanding the language used by a physician, virtually the same percentage of those with WS physicians and those whose physicians were elsewhere reported such difficulties (37\%). The same holds true for problems understanding a physician's instructions to the patient regarding a health problem (see Table 28 ).

Table 28

Problems Understanding Physician's Instructions (Native Respondents Only)

Regular Source of Non-Emergency Care

Westside Elsewhere chì sq $=0.189$, df $=1$, sig $=0.664$
Reporting a Problem

\begin{tabular}{cr} 
Yes & No \\
\hline $23(24.5 \%)$ & $71(75.5 \%)$ \\
$9(19.6 \%)$ & $7(80.4 \%)$ \\
$9=0.664$ & \\
\hline
\end{tabular}

\section{TRADTIONAL MEDICINE}

It is apparent that traditional Indian healing methods, and recourse to Indian healers, still remains important for the Native population in Canada. Given that many Native people use both the 
Western medical system and traditional medicine, either simultaneously or serially, and that many Natives at some point in the past have had direct contact with traditional healers, it is important that urban Native health research assess the extent to which traditional medicine is available and is utilized in the city, and address the question of adequacy of that access.

Since traditional medical systems are most commonly associated with "Indian" cultural traditions, those systems, and their healers, will be referred to as "Indian." However, it must be emphasized that there are Métis healers, although their medical tradition is likely little different from that of the Indian healers.

Native respondents were asked a variety of questions related to traditional medicine,their belief in it and their utilization of it.

\section{Indian Healers in the Clinic}

Fully $60 \%$ of the Native respondents stated that they would like to see Indian healers in a clinical setting (with emphasis on the Westside). There exists some difference between females and males, with $67.1 \%$ of the females and $49.0 \%$ of the males indicating a desire to see healers in the Clinic (chi sq=3.36, $\mathrm{df}=1$, sig=0.067). More status Indians $(62.8 \%$ ) than non-status Indians $(53.3 \%)$ and Métis $(50 \%)$ indicated their desire to have healers in the Clinic.

In terms of first spoken language, $69.0 \%$ of those whose first language was Indian would like to see healers in the Clinic, compared with $50.0 \%$ of those whose first language was non-Indian (chi $s q=3.79, d f=1, s i g=0.05)$. Similarly, more respondents who currently speak an Indian language (68.5\%) than who do not (38.9\%) would like to see Indian healers in the Clinic (chi sq=8.19, df=1, sig=0.004), and more $(76.4 \%)$ would actually consult with the healer compared with current non-Indian language speakers $(47.4 \%$ ) (chi $s q=8.98, d f=1, s i g=0.003$ ). Furthermore, $81.3 \%$ of those speaking their Indian language "most of the time" indicated a desire to have Indian healers in the Clinic, compared with $70.0 \%$ of those speaking their Indian language "half of the time," $71.4 \%$ of those speaking "occasionally," and $53.8 \%$ of those speaking "rarely or never" (Mann-Whitney $U=685$, prob $=.075$ ). Similarly, some $93.8 \%$ of those speaking an Indian language most of the time, compared with $61.5 \%$ of those rarely or never speaking it, indicated that they would consult a healer in the Clinic (Mann-Whitney $U=511, p r o b=.035$ ).

There was little difference in educational level, income or age between those wanting healers in the Clinic, and those not wanting them.

The reasons for wanting to see healers in the Clinic can be divided into two basic categories: a belief in Indian medicine and its efficacy, or what could be termed a cultural affinity; and a desire to learn more about it. The reasons for not wanting healers in the Clinic were more varied, ranging from 
a lack of belief (or cultural disaffinity), fear (for instance, "bad medicine," or illness caused through a form of sorcery or witchcraft), or a belief that, while Indian medicine is efficacious, it would not be proper for it to be administered in the Clinic.

Overall, of those offering a positive explanation regarding healers in the Clinic, $50.7 \%$ expressed a cultural affinity, and another $29.3 \%$ said that they knew little about Indian medicine or the work of healers but would like to learn more. Of those viewing healers in the Clinic negatively, $60.8 \%$ expressed an attitude of disaffinity, or lack of belief in Indian medicine. Interestingly, a further $13.7 \%$ expressed a belief in Indian medicine but felt that it would not be appropriate to have healers in the Clinic, and another $13.7 \%$ expressed a belief in and fear of Indian medicine. When we combine both the positive and negative attitudes toward the presence of healers in the Clinic, we discover that at least $41.0 \%$ of the Native respondents expressed some belief in Indian medicine; it is quite likely that this percentage would have been even higher had we addressed this issue more directly.

Even though $60 \%$ of the Native respondents would like to see Indian healers in a clinic, some $67.7 \%$ would actually consult with a healer were one available. Again more status Indians (73.7\%) than non-status Indians (53.3\%) and Métis (47.1\%) would consult (chi $s q=6.29, \mathrm{df}=2, \mathrm{sig}=0.043$ ), as would more females $(72.7 \%)$ than males $(60.0 \%)$. More Native individuals whose first language was an Indian language $(80.0 \%)$ than non-Indian $(54.5 \%)$ would consult with a healer in a clinic (chi $s q=8.15$, df $=1$, sig=0.004).

There was little difference in education or income between those who would consult with the healer and those who would not. Interestingly, the mean age of those who would consult was lower (28.8 years) than for those who would not consult (33.1 years) $(T=-2.28, d f=125$, prob $=0.024)$.

The proposed reasons for a consultation with a healer in the Clinic varied, but there were two broad types. We might call the first type "somatic," in other words the seeking of relief from pain or disease, and we might call the other "psychological," in other words seeking relief from spiritual, personal or emotional problems. The somatic consultations demonstrated a great variability, with respondents indicating that they might seek traditional treatment for anything from a cold to cancer and for diseases considered "terminal" by Western medicine, or for other chronic problems that Western medicine had been unable to resolve. The psychological problems likewise showed some variability, and although many respondents were reluctant to explain the specific kinds of problems, some did mention that a consultation would be undertaken in cases of "bad medicine." 


\section{Previous Contact with Traditional Medicine}

None of the Native respondents had previously consulted with an Indian healer concerning the health problem that brought them to the WS on the day of their interview. A small number of the status Indians $(10.3 \%, n=6)$ and Métis $(14.3 \%, n=2)$ indicated that they planned to consult an Indian healer about their current health problem; and more females $(12.5 \%, n=7)$ than males $(3.8 \%, n=1)$ likewise indicated their intent to see a healer. Only a small minority $(4.7 \%, n=6)$ had actually seen an Indian healer within the last year, and all of these were status Indians. In all cases, the consultation took place outside Saskatoon, usually on a reserve. Furthermore, in all cases the respondent held the belief that the treatment had worked.

Many more respondents (30.8\%) had seen an Indian healer at some point in their life. While there was little difference between males and females in this regard, those having seen a healer registered a higher mean age (33.2 years) than those not having seen a healer (29.4 years) ( $t=2.11$, $\mathrm{df}=82.3$, prob=.038). More respondents who currently speak an Indian language $(38.3 \%)$ reported having seen an Indian healer than those (12.2\%) who had not (chi $s q=8.00, \mathrm{df}=1, \mathrm{sig}=0.005$ ). However, there was little difference between individuals who currently speak their Indian language "most of the time" and those who speak it "rarely or never." Of those who had never seen a healer, the leading reason was either that they did not know enough about Indian medicine, or else they had simply never required the services of an Indian healer. Interestingly, among those whose first language was not an Indian language, $22.2 \%$ explained that they did not believe in Indian medicine, and $35.6 \%$ stated that they did not know enough about it; this compares with only $4.4 \%$ of the Indian first language speakers who did not believe in it, and $24.4 \%$ who did not know enough about it (chi sq=15.00, df=5, $\mathrm{sig}=0.01$ ). For those who currently speak a Indian language, only $10.9 \%$ stated they did not believe in Indian medicine, and $\mathbf{2 0 . 0 \%}$ stated they did not know enough about it to use it. This compares with $19.4 \%$ and $44.4 \%$ respectively for those Native respondents who do not currently speak an Indian language (chi $s q=10.89, \mathrm{df}=5$, sig=0.05).

A smaller percentage (17.2\%) had seen only an Indian healer for a particular health problem, and there was little difference between the sexes. Further, $17.1 \%$ had seen both an Indian healer and a Western doctor (or healers and doctors) for the same problem during their past. More females (22.5\%) than males (9.6\%) indicated having seen both Western and Indian healers.

Of those with an Indian first language, 20.0\% reported having seen only an Indian healer for a health problem, compared with $\mathbf{1 4 . 0 \%}$ for those with a non-Indian first language. The results for current speakers and non-speakers of an Indian language were similar. More current Indian speakers 
(19.8\%) than non-speakers $(9.4 \%)$ had seen both an Indian healer and a Western doctor for the same health problem.

Very few $(5.1 \%, n=8)$ of the respondents had undergone a traditional sweatlodge ceremony ("sweat") in the last year. In every case the sweat occurred outside of the city.

The utilization of various kinds of Indian herbs and other medicine is fairly extensive, though one must keep a broad view of what constitutes "medicine" within the Indian healing tradition. Some $43.9 \%$ of the respondents reported such usage within the last year, although for many of these the medicine was sweetgrass, burnt usually to ward off misfortune and illness (including spiritually-caused illness through sorcery or witchcraft, which respondents usually referred to as "bad medicine" or "Indian medicine"). The status Indians in particular reported a high usage, with $58.4 \%$ using some form of Indian medicine in the previous year. These medicines were occasionally directed by an Indian healer, but many were of the generic type. There was little difference between the sexes in the utilization of traditional medicine.

Among those whose first language was an Indian one, 57.0\% reported the utilization of Indian herbal medicines and/or sweetgrass, compared with $32.5 \%$ of those whose first language was not an Indian language (chi $s q=9.95$, $d f=2, s i g=0.007$ ). But the difference was not significant for current Indian language speakers in comparison with non-speakers. There was also little difference in utilization between those who speak their Indian language "most of the time" and others who speak it less.

\section{Beliefs conceming Indian and Western Medicine}

Most respondents $(60.8 \%)$ stated that Indian healers could handle certain problems better than Western doctors. An even higher percentage (85.5\%) stated that Western doctors could handle certain kinds of problems better than Indian healers. The qualitative data did not reveal a clear distinction between "Indian" illness, etiology and treatment on one hand, and "Western" on the other.

More males $(73.5 \%)$ than females $(52.1 \%)$ believed that Indian healers could handle certain kinds of problems better than Western doctors (chi $s q=4.69, \mathrm{df}=1, \mathrm{sig}=0.03$ ). There was little difference between the sexes in their views of Western doctors.

More individuals whose first language was an Indian one (67.2\%) than those whose first language was not Indian (52.9\%) stated that Indian healers could handle certain problems better than Western doctors. However, significantly more current Indian language speakers (68.2\%) than non-speakers (40.6\%) stated that Indian healers could handle certain kinds of problems better (chi $s q=6.37, \mathrm{df}=1, \mathrm{sig}=0.012$ ). Slightly more non-Indian first language speakers $(88.7 \%)$ than Indian first 
language speakers (82.3\%) stated that Western doctors could treat certain problems better than Indian healers. Similar results were obtained for current Indian speakers vs. non-speakers.

The kinds of problems which respondents felt Indian healers could handle better than Western doctors varied extensively from the somatic to the psychological. Some respondents felt that Indian healers could handle various diseases and disorders:

"They can heal like an ordinary aspirin."

"They can cure cancer."

II think they could cure people with sicknesses without having to operate on the person."

Other somatic problems that respondents felt an Indian healer could handle better included colds and flu, pneumonia, headaches, kidney problems, female infertility, psoriasis and gangrene. It was also noted by some that Indian healers were often able to heal in situations where Western medicine had failed.

A variety of "psychological" and spiritual problems could also be handled better, including "bad medicine:"

"If somebody does something to someone and takes something of someone's, they can really do bad stuff to you. [Indian healers are] for people who use Indian medicine ways. [Patients] need to go to an Indian doctor to get fixed."

"When a person's in contact with bad medicine."

"People who go to see one [Indian healer] are spiritual people who believe in his powers. Mentally, they can help people."

Respondents stressed the view that spiritual and personal problems could best be handled by an Indian healer, if the person believes in Indian medicine.

Respondents also expressed a variety of views on the kinds of problems Western medicine could better handle. Many of these views centred on the advanced technology available to doctors, including $X$-rays and surgical techniques. There was also some emphasis on the better medicines of the Western doctors. Interestingly, no respondents mentioned psychological, emotional, spiritual or personal problems as being better handled by Western doctors.

\section{Traditional Medical Services in Saskatoon}

Very few of the respondents (5.1\%) indicated that they knew of an Indian healer in Saskatoon, although $58.8 \%$ indicated their belief that they could find one through the Native network if they so desired. There was little difference between current Indian language speakers and non-speakers in 
their knowledge of, or ability to find, a healer in the city. Similarly, there was little difference between those who currently speak their Indian language "most of the time' and those who speak it less often.

\section{SUMMARY AND CONCLUSIONS}

Overall, this study has demonstrated that, generally speaking, both the Native and non-Native respondents have fairly extensive contact with the urban health care system, and there are many similarities in their patterns of utilization. The data would suggest that we reject our general hypothesis that Natives would exhibit "underutilization" or "inappropriate" utilization of the urban health care system in comparison with non-Natives. Insofar as the Native and non-Native respondents demonstrated similar health care behaviour patterns, these may be the result of similar socio-economic circumstances, and their marginalized position within the urban milieu.

Returning to our broad research questions delineated earlier in this report, we are able to offer the following general observations while mindful of the complexity of the specific issues themselves. 1. Poverty, culture and language all have a role to play in understanding the adaptation of Native people to the urban health care system. The broad similarities that existed between disadvantaged Native and non-Native respondents in their patterns of utilization suggest that poverty is, indeed, of primary importance. Specific problems, such as paying for medicines and travel to physicians' offices were evident. Having a lower mean income and an even greater degree of unemployment, the Native respondents indicated even greater problems in these areas.

In some contexts, cultural factors are obviously important, such as in the preference of Natives for convenience in health care delivery and for access to traditional medical services.

Among the Native population itself, language was also an important factor. All our Native respondents were bilingual (English and an Indian language) to some extent, yet those with the greatest link to their Indian languages demonstrated both greater clinical communication problems and greater affinity for Indian medicine in the urban milieu. While the efforts of the Westside Clinic staff to eliminate communication problems are valiant, the fact that such difficulties remain underscores the extent of the problem. It is quite likely that communication problems between Native patients and other health care providers are even greater where few attempts at effective communication are made.

Related to communication problems are problems of literacy. Many respondents had difficulty reading the label of a bottle of medicine, identifying its use, and determining the proper dose and frequency of administration. It follows, then, that both prescription and non-prescription medicines may not be taken in an appropriate manner by many of the respondents due to their inability to read the directions. 
2. Other socio-economic factors also proved to be relevant to our understanding of utilization patterns. In particular, females, both Native and non-Native, tended to demonstrate greater utilization of the health care system, and better attitudes toward health, than males. Age, marital status and various measures of economic standing were also important in certain contexts, as were measures of intra-city mobility and length of residence. The most problematic sub-population in terms of their avoidance of the urban health care system is not Native, but rather consists of single non-Native males. 3. Both the Native and non-Native populations demonstrated extensive utilization of a variety of urban health care services and facilities. Natives demonstrated a greater utilization of the Westside Clinic, while non-Natives preferred physicians in private practice. Hospital emergency departments were also key sources of primary health care. St. Paul's Hospital was a favourite source of care for Natives, and while non-Natives also utilized it they tended to use the services of the city's other two hospitals to a greater extent that the Natives. Convenience, as measured by the proximity of the facility and its hours of operation, seemed more important to the Native respondents, while a commitment to a particular physician was more important to the non-Natives when selecting a facility. These differences may reflect differences in culture, belief system and experience. However, both the Native and the nonNative respondents demonstrated a commitment to a particular facility, and to a particular physician or set of physicians, and hence established a continuity in the delivery of medical care regardless of the facility itself.

In general, dental and optometric services were underutilized by both populations.

4. The Native population in general demonstrated a strong attachment to the traditional medical systems, with many respondents indicating a clear desire for more formal access to these health services. Actual utilization of traditional medical services in the city were low, with most contacts apparently occurring in the reserve context. An unmet health need may exist in this area, and certainly more research is required.

The impact of the Westside Clinic was demonstrated by the research, especially on the health care behaviours of Native respondents. The tendency to have regular contacts with physicians and to utilize hospital emergency departments at times when other facilities were unavailable was noted among regular Westside users. However, communication problems between physicians and Native patients proved to be pervasive among users of both the Westside and other health care facilities and services.

Some interesting results directly challenge commonly held stereotypes about Native utilization of the health care system. For instance, this study reveals that, in general, the Native urban dwellers who were interviewed have as much contact, and in some cases more contact, with the urban health care system than do non-Natives of a similar socio-economic level. Natives do not demonstrate a 
significantly higher degree of reliance on hospital emergency department services, nor do they demonstrate a greater reluctance to establish an ongoing relationship with a particular physician or primary care institution. Indeed, Native utilization of ED services, and Native attitudes concerning contact with family physicians and specific medical services, could be defined as more "appropriate" and conducive to good health than for the non-Natives. This fact may well be anomalous and primarily the product of the existence of the Westside Clinic, the staff of which work diligently to make the Clinic an acceptable and comfortable place for Native patients. If true, then the Westside Clinic model would appear to be one worthy of emulation in other parts of the city and in other cities as well.

The results of the research do not mean that health care delivery is necessarily acceptable or optimum for either Native or non-Native urban poor, but they do point out that the non-Native population is as problematic as the Native population in this area of the city.

The study in no way attempted to measure health status. Contact with the urban health care system occurs as a result of many factors, including knowledge about and attitudes toward that system as well as knowledge of illness in general and onset of an illness episode. While the respondents in this study demonstrated what appears to be extensive contact with the urban health care system, this can not be taken to mean that this system is sufficient or appropriate for their needs, nor that the respondents are particularly healthy. Extensive contact may be the result of the endemic chronic and acute illness and injury that many believe characterizes the disadvantaged urban population. In other words, they may make extensive utilization of the urban health care system because of their continuing ill-health and misfortune. Further, the two key health care institutions in the study area, the Westside Clinic and St. Paul's Hospital, are facilities relatively unfettered by rules of conduct, dress, appointment making, and so on, which appear to be important factors in attracting our respondents. We cannot say at this time that their utilization of the health care system is sufficient given their particular life-circumstances and patterns of morbidity. Whether their utilization is greater or lesser than for other segments of the urban population is also a question that requires further research.

This study has extended our knowledge about the health care utilization patterns of both Natives and non-Natives in one area of Saskatoon, and the extent to which its results are meaningful for other parts of the city or other urban centres remains to be seen. It may very well be that outside of the hinterland serviced by the Westside Clinic, health care utilization patterns are considerably different, among not only the poor but also the more affluent Natives and non-Natives, and that problems utilizing the health care system exist. Many of the results reported here are similar in a very general way to those disclosed in the Ontario, Winnipeg, Calgary, Edmonton and Vancouver studies discussed earlier in the paper: Native people seem to be making extensive use of urban health care 
facilities, although such a measure by itself says nothing of "appropriate" or "optimum" utilization nor does it directly indicate anything about health status. It is clear, however, that efforts must be made to avoid assuming that Native people in urban areas automatically have problems deciphering available health care services. Similarly, we must also be careful not to assume automatically that Native patterns of utilization and health behaviours are culturally related. This research underscores the significance of socio-economic status in understanding the reactions of individuals, both Native and non-Native, to the urban health care system. When similar utilization patterns emerge among people of varied Indian and European backgrounds whose common bond is their poverty and marginality, cultural explanations of behaviour patterns seem overly simplistic. 


\section{REFERENCES}

Alberta. Native Counselling Services of Alberta and Native Affairs Secretariat. Demographic Characteristics of Natives in Edmonton. Edmonton: Native Affairs Secretariat, 1985.

Anderson, David L. "Government Policies and Programs Relating to People of Indian Ancestry in Saskatchewan." In Raymond Breton and Gail Grant, eds. The Dynamics of Government Programs for Urban Indians in the Prairie Provinces, pp. 203-319. Montreal: Institute for Research on Public Policy, 1984.

Calgary. Native Needs Assessment. Calgary: City of Calgary, Department of Social Services, 1984.

Canada. Department of Indian Affairs and Northern Development. Indian Conditions: A Survey. Ottawa: Department of Indian Affairs and Northern Development, 1980.

Clatworthy, Stewart and Jeremy Hull. Native Economic Conditions in Regina and Saskatoon. Winnipeg: Institute of Urban Studies, 1983.

Farkas, Carol S. and Chandrakant P. Shah. "Public Health Departments and Native Health Care in Urban Centres." Canadian Journal of Public Health, 77 (1986): 274-276.

Maidman, Frank. Native People in Urban Settings: Problems, Needs and Services. Report of the Ontario Task Force on Native People in the Urban Setting. Toronto, 1981.

McCaskill, D.N. The Urbanization of Canadian Indians in Winnipeg, Toronto, Edmonton and Vancouver." Ph.D. thesis, York University, Toronto, 1979.

Mears, Bronwen, Karen Pals, K. Kuczerpa, Maureen Tallio and E. Alan Morinis. IIIness and Treatment Strategies of Native Indians in Downtown Vancouver: A Study of the Skid Row Population. Vancouver: Health and Welfare Canada, 1981.

Saskatchewan Indian and Métis Friendship Centre. "Saskatoon Native Health Liaison Project." Unpublished proposal, 1982.

Saskatoon. Healthy Mother-Healthy Baby. Saskatoon: Community Health Unit, n.d.

Saskatoon Star-Phoenix. 'A People Apart: Natives in Saskatoon." Special Report, 7 October, 1986.

Senior Citizens' Provincial Council (Saskatchewan). A Study of the Unmet Needs of Off-Reserve Indian and Métis Elderly in Saskatchewan. Regina: Senior Citizens' Provincial Council, 1988.

Shah, Chandrakant P. and Carrol Spindell Farkas. The Health of Indians in Canadian Cities: A Challenge to the Health Care System." Canadian Medical Association Journal, 133,1

(1985): 859-863.

Stanbury, W.T. Success and Failure: Indians in Urban Society. Vancouver: University of British Columbia Press, 1975. 
Winch, Robert F. and Donald T. Campbell. "Proof? No. Evidence? Yes. The Significance of Tests of Significance." American Sociologist, 4,2 (1969): 140-143. 